\title{
Teología de los signos de los tiempos. Antecedentes y prospectivas del Concilio Vaticano II
}

Las siguientes reflexiones son fruto de un diálogo al cual han sido invitados por el "Centro Teológico Manuel Larraín" diversos católicos deseosos de pensar su fe de cara al tercer mileno.

Monseñor Manuel Larraín ha dejado inestimables testimonios de su participación en el Concilio Vaticano II y de los nuevos tiempos que él, sabia y proféticamente, vislumbró que para la Iglesia traería este acontecimiento eclesial. En sus escritos reunidos por el padre De la Noi se puede verificar aquello (1).

Ahora bien, dado que este año tendrá lugar en Roma en octubre la canonización del beato Alberto Hurtado, un adelantado al igual que Larraín a muchas de las intuiciones directrices del último concilio, vale la pena remitirse a una parte de la homilía de Manuel Larraín, en ese tiempo obispo de Talca, en la misa de funeral del padre Hurtado, para leer allí parte de la inspiración que ha permitido la creación del "Centro" antes mencionado y a lo cual el artículo que presentamos a continuación quiere ser un pequeño aporte. Me refiero a la temática de los signos de los tiempos: "El padre ha meditado muchas veces la palabra de Jesús en San Mateo: 'Se le acercaron los fariseos y saduceos para tentarle y le rogaron que les mostrara una señal del cielo. El respondiéndoles, les dijo: Por la tarde, decís hará buen tiempo, si el cielo está arrebolado; y a la mañana, hoy habrá tempestad, si en el cielo hay arreboles oscuros. Sabéis discernir las señales de los tiempos nuevos"”. Y no quiso que para los católicos de Chile pudiera aplicarse el reproche de Jesús de "no saber discernir las señales de los

(1) Cf. Mons. Manuel Larraín, Escritos completos, vol. 1, La Iglesia en su vida íntima, Santiago 1976, especialmente 89-166; Escritos completos, vol. 3, La Iglesia en su espiritualidad-El laico cristiano, Santiago 1978, sobre todo 299ss. Se puede ver cómo Larraín habla de los signos de los tiempos desde la óptica de una teología de la encarnación consecuente, asimismo como de una teología del "trueque" cristológico a la que nos referiremos más adelante. En sus escritos sobre el Vaticano II se descubre también una profunda reflexión sobre la relación entre Iglesia y mundo, en donde este no es sencillamente lo "otro", sino que determina constitutivamente la misión de la Iglesia y por ello -ontológicamente habando- su ser (el autor no tiene inconveniente para hablar de la determinación histórica de afirmaciones, como él mismo las llama, "ontológicas"). De especial interés resultan igualmente sus reflexiones sobre la pobreza concreta de Latinoamérica, desde un punto de vista "ontológico-histórico", situación que constituye al mundo como historia en el lugar desde donde el cristiano debe leer y escrutar los signos de la voluntad del reino de Dios (cf. vol. 1, 152ss). 
tiempos nuevos". Quiso, en cambio, que su acción fuera tanto más realista cuanto más alto era su ideal. Y que para ello se penetraran de la gravedad de los tiempos que vivimos, se enfrentaran al hecho de nuestra paganización creciente y sacaran de ahí, en forma viva y apremiante, la conciencia de su dolor apostólico. Y fruto de este realismo apostólico fue su trascendental libro ¿Es Chile un país católico? El título y la tesis tenían que chocar. ¡Es tan dulce dormirse sobre la ilusión de una cifra estadística! Es tan fácil excusarse de la acción profunda, diciendo: “¡Chile es un país católico!”. ¡Es tan cómodo abandonar los problemas vitales de la Iglesia que exigen sacrificio constante y reemplazarlo por unas cuantas manifestaciones bullangueras! Pero el apóstol de verdad ha sido puesto como "dardo agudo" que se clava en las carnes dormidas, como vigía que rompe con su grito estridente el silencio cómplice de la noche. Y, pese a las incomprensiones y a las críticas, el libro quedó como una interrogante angustiosa que golpea, urgiendo, las conciencias cristianas: “¿Es Chile un país católico?". Si un gran examen de conciencia comienza hoy a hacerse entre los católicos chilenos, si la distinción entre lo vital y lo aparentemente cristiano va penetrando en muchos espíritus, si la necesidad de una acción profunda que nace de una vida íntegramente vivida se hace sentir más fuertemente, si, en una palabra, nuestra acción se basa en realidades que no por amargas dejan de ser realidades, tendremos en el futuro que señalar la audacia de un apóstol que, con magnífica libertad, dijo fuerte lo que su mente veía, y supo de esa misma realidad sacar las normas de la acción" (2).

En el siguiente artículo queremos reflexionar sobre una idea directriz del último concilio ecuménico, como lo es la recuperación de las dimensiones de "tiempo" e "historia" como constitutivas para el pensar teológico y la autocomprensión de la Iglesia, lo que se ve reflejado en el impulso que los textos conciliares dan a la temática de los "signos de los tiempos" -ya introducida a propósito de la homilía recién citada-, lo que consideramos una oportunidad que confiere una nueva relevancia a la identidad cristiana en diálogo con la modernidad.

Para nuestro propósito procederemos en cinco pasos. Primero señalaremos, de manera introductoria, cómo el concilio implica para la teología una invitación perenne a repensar formalmente su relación con las peguntas que surgen de los tiempos actuales como elementos constitutivos de su ser, a pesar que el concilio en muchos aspectos haya sido superado en los contenidos (aspecto material). En un segundo paso, nos abocaremos a precisar cuál es nuestra postura frente a un punto clave, como lo son las diversas posibilidades de realizar una hermenéutica del concilio. A propósito de este punto esperamos indicar de qué modo el concilio representa, dentro de la continuidad, una "revolución copernicana" (F. Kaufmann) a la hora de pensar estructuralmente las relaciones entre Iglesia y teología, y mundo e historia. En un tercer paso desarrollaremos los antecedentes cercanos e inmediatos que, a nuestro juicio, más influyeron en el aggiornamento que supuso el concilio para la Iglesia, en perspectiva a recuperar a la historia real y el tiempo actual para la teología en vistas a profundizar la temática de los "signos de los tiempos". En un cuarto momento analizaremos, a propósito de la conocida tesis de Rahner sobre el concilio como "corte" con respecto a su historia precedente, la relación que este

(2) Cf. www.puc.cl/hurtado. 
evento eclesial establece entre Iglesia, Espíritu Santo e historia. Finalmente, en un quinto paso, desarrollaremos la problemática de los "signos de los tiempos" como, a nuestro juicio, la gran novedad (a veces desentendía y estrechamente interpretada) y tarea del Vaticano II para la teología y el cristianismo actual. Terminaremos con una breve conclusión que se propone mostrar de qué manera el concilio supone una superación del carácter "extrínseco" de la relación Iglesia-mundo y de qué modo la teología tiene aquí un rol clave que jugar.

\section{EL VATICANO II Y UN NUEVO MÉTODO PARA AFRONTAR LAS PRE- GUNTAS DEL MUNDO}

Como toda estructura viva, y no solo como una sustancia atemporal y ahistórica o un sistema cerrado (3), también la Iglesia ha tenido que reaccionar desde sus orígenes a los estímulos internos y externos que le imponían, por decirlo así, que se redefiniera en el contex to humano de su propio tiempo (4). En la comunidad primitiva, por ejemplo, se planteaban estas preguntas entre otras: ¿qué condiciones imponer a los paganos que abrazan el Evangelio? (como se ilustra por ejemplo en el incidente entre Pablo y Pedro a propósito de la circuncisión), ¿cuál es el sentido de las relaciones sexuales?, ¿es lícito casarse ante la inminencia de la venida del Señor (parusía)?, ¿qué relación existe entre la ley mosaica, la sabiduría griega y el Evangelio? La historia sucesiva de la Iglesia fue incrementando el número de tales preguntas. Y esto por dos razones: porque iban surgiendo nuevas y porque las respuestas anteriores resultaban insuficientes: ¿qué hacer con las Escrituras hebreas, qué hacer con quienes habían pecado gravemente tras el bautismo, qué hacer con quienes en tiempo de persecución habían renegado de la fe (apóstatas), qué hacer con quienes habían comprado su ordenación (simoníacos), qué hacer ante los abusos de poder en la Iglesia, qué hacer ante la corrupción de la vida cristiana en el vértice y en la base? Pero también: ¿cuáles son los derechos de los indios (piénsese en los intentos de reflexión de un Bartolomé de la Casas o de un Francisco de Vittoria), qué quiere decir llevar el Evangelio a una sociedad como la china (una pregunta ya formulada en su tiempo por un Mateo Ricci y hoy por cierto más acuciante que nunca), cuál es la relación entre la razón moderna y la revelación cristiana (como se plantea por ejemplo en la encíclica Fides et ratio de Juan Pablo II)?

(3) Cf. C. Schickendantz, Cambio estructural en la Iglesia como tarea y oportunidad, Córdoba 2005 (con sugerentes observaciones con respecto al Vaticano II); M. Kehl, ¿Adónde va la Iglesia? Un diagnóstico de nuestro tiempo, Santander 1997; íd., La Iglesia. Eclesiología católica, Salamanca 1996; S. Wiedenhofer, Eclesiología, en: Th. Schneider (ed.), Manual de Teología Dogmática, Barcelona 1996, especialmente, 665ss.707ss; P. Hünermann, Konkretion und Geist. Der qualitative Sprung im Verständnis von Weltkirche, Theologische Quartalschrift 165 (1985), 216-227; W. Kasper, Unicidad y universalidad de Jesucristo, en: A. Vargas Machuca (ed.), Jesucristo en la historia y en la fe, Salamanca 1977, 271-274; S. Madrigal, Eclesiología en devenir: el estudio de la Iglesia en el ciclo institucional de la teología, en: G. Uribarri (ed.), Fundamentos de teología sistemática, Bilbao 2003, 137-178.

(4) Cf. las inspiradoras reflexiones de M. Eckholt al respecto a partir del pensamiento de M. de Certeau, Nicht ohne Dich. Der verletzte Wanderer und der fremde Gott. Eine Annäherung an Michel de Certeau SJ, en: P. Schmitt (ed.), Der dunkle Gott, Stuttgart 2005 (por aparecer). 
También hoy existen numerosas preguntas: desde la cuestión del uso de las Escrituras a la del ministerio petrino, desde la religiosidad "global" a la cultura postmoderna, desde las "teologías de la liberación" al futuro del ecumenismo cristiano, desde una revaloración postmoderna del politeísmo en la filosofía y las ciencias de la religión hasta el repensar la idea de un único Dios desde el misterio trinitario como posibilidad de la subsistencia de lo particular y contingente en el todo, desde la reflexión de cómo plantear hoy la idea de sujeto y persona humana -y en última instancia la interrogante por la libertad- a partir del misterio divino hasta las preguntas que nacen de la bioética, etc.

La cuestión que queremos tratar en las siguientes reflexiones es la de si el Concilio Vaticano II (5) nos puede ayudar, y en qué modo, a responder a las preguntas que surgen hoy en las Iglesias cristianas (6). Más exactamente nos preguntamos si en el último concilio no se estableció un método, de algún modo nuevo, de afrontar las grandes preguntas que la historia plantea a la Iglesia. La cuestión es tanto más urgente cuanto que no faltan las incertidumbres. Este concilio, ¿no pertenece ya al pasado? (acordémonos aquí del refrán popular citado por Hegel, con consecuencias ontológicas: "en Saubia algo había pasado hace tanto tiempo, que ya no existe"). Si tuvo el mérito de cerrar una etapa de la Iglesia, ¿qué nos puede ofrecer ahora? Y, suponiendo también que las decisiones del Concilio Vaticano II sean todavía de alguna utilidad, ¿cómo distinguir entre esas decisiones, dado que todos (es decir, todo el espectro eclesial, con excepción de algunos movimientos minoritarios de tipo lefevristas) hasta quienes piensan de manera opuesta, parecen apelar a él? (7)

El recurso al concilio, en efecto, corre el riesgo de convertirse para muchos casi en un lugar común (algo análogo, por ejemplo, como sucede en la actualidad cuando se apela a los términos "democracia" o "bien común"). Pero la consideración de la diversidad de las interpretaciones de ese lugar común conlleva a interrogarse: ¿es posible no hacer violencia -hermenéutica- al Vaticano II?, ¿se pueden reconocer en él, respetando su verdad histórica, "indicaciones formales" útiles para las preguntas que nos planteamos tras dos milenios de historia del cristianismo?

Aquí utilizamos la expresión "indicación formal” en un sentido análogo a la que a esta le otorga M. Heidegger (8).

(5) Las referencias a los textos del Vaticano II y del magisterio -salvo algunos textos de Juan XXIIIse toman de E. Denzinger/P. Hünermann (eds.), El magisterio de la Iglesia, Barcelona 1999 (en adelante DH).

(6) Cf. K. Lehmann, Der doppelte Aufbruch - und was nun? Standortbestimmung 30 Jahre nach dem Vatikanum II und 20 Jahre nach der Gemeinsamen Synode, en: A. Käuflien/T.Licht (eds.), Wo steht die Kirche?, Karlsruhe 1998, 17; id., Zwischen Überlieferung und Erneuerung. Hermeneutische Überlegungen zur Struktur der verschiedenen Rezeptionsprozesse des Zweiten Vatikanischen Konzils, en: A. Autiero (ed.), Herausforderung Aggiornamento. Zur Rezeption des Zweiten Vatikanischen Konzils, Altenberge 2000, 95-110.

(7) Cf. J.-H. Tück, 40 Jahre Zweites Vatikanische Konzil. Vergessene Anstöße und Perspektiven, Theologie und Glaube 93 (2003), 48-59.

(8) Cf. ante todo Grundprobleme der Phänomenologie, (GA 58), Frankfurt 1992, especialmente 143.150.236.240; ver también, Phänomenologie des religiösen Lebens, (GA 60), Frankfurt 1995, sobre todo, 3ss. 35-65; Phänomenologie der Anschauung und des Ausdrucks, (GA 59), Frankfurt 1993. 
A inicio de los años veinte Heidegger lleva adelante una reflexión sobre la filosofía (método, alcance, conceptualización, etc.), en la cual da contorno a su propia posición dentro de la fenomenología (Husserl). Lo característico de esa reflexión es la crítica a "lo teórico", como marco inapropiado del filosofar, porque aparta a la filosofía de su fuente y cuestión, que es la vida prefilosófica. El programa filosófico de Heidegger en esta época es la "fenomenología de la vida fáctica". Parte de la reflexión de Heidegger por esos años toca el tema de la conceptualización filosófica, es decir, la cuestión acerca del carácter y función de los conceptos filosóficos. Allí opone Heidegger (sobre todo en Problemas fundamentales de la fenomenología) dos funciones de los conceptos, correlativas a dos modos de usarlos: los "conceptos ordenadores" (Ordnungsbegriffe) y los "conceptos expresivos" (Ausdrucksbegriffe). Los primeros son propios del uso clasificatorio de la lógica, mientras los segundos son utilizados en su función expresiva. Por "expresión" entiende aquí Heidegger la remisión a un contexto o "nexo de sentido" (el "Sinnzusammenhang" que después desarrollará también Gadamer en su hermenéutica) pertinente. El uso de un "concepto expresivo" consiste en estar remitido al contexto de sentido correspondiente: pero ese "estar remitido" no es mera pasividad. Por el contrario, se trata de la tarea de interpretación como actualización del nexo de sentido "originario" del concepto contra los ocultamientos y desfiguraciones imperantes (así, por ejemplo, un concepto puede remitirnos a su contexto originario en la lengua y cultura griegas, pero esa remisión significa a la vez hacerse cargo de la distancia entre el hoy y los griegos y hacer una crítica de la tradición y traducción que abonan esa distancia). Para dar cuenta de modo más claro de esta estructura de los conceptos filosóficos, Heidegger utiliza el término "indicación formal": los conceptos "indican" en cuanto remiten al filósofo a una situación interpretativa y lo ponen ante la tarea de la interpretación. Heidegger caracteriza a esta función indicativa como "formal", tomando en cuenta la distinción husserliana entre formalización y generalización. Si consideramos como "mundo" a la situación de comprensión o interpretación, entonces la función indicativa de los conceptos filosóficos constituye una "apertura de mundo", en la medida en que instala al intérprete (el filósofo que utiliza el concepto) en un determinado complejo de "nexos de sentido". Lo interesante aquí es que Heidegger no afirma de manera ingenua que los conceptos nos remitan a un contexto ya pasado (como si dijésemos que los conceptos filosóficos nos remiten al "mundo griego" del que hablan los historiadores). Para Heidegger es central la idea según la cual esa remisión reinaugura el problema de la "distancia" que nos une y nos separa con las fuentes. Como se puede apreciar, en el horizonte temático de la teoría de la "indicación formal" está el problema de la remisión a la "fuente", esto es, al "origen" (y el "origen" [Ursprung] es para Heidegger en esta época -inicio de los años 20- tanto el origen histórico de la filosofía [los griegos], cuanto la vida prefilosófica). En resumen, la teoría heideggeriana de la "indicación formal" es la elaboración de la cuestión del uso y función de los conceptos filosóficos en el marco de la propuesta de una "fenomenología hermenéutica". Se trata de una teoría consecuente con la idea según la cual la filosofía es: $a$. un modo de interpretación/comprensión, vinculado estructuralmente a la "precomprensión" de la vida prefilosófica; $b$. un modo de interpretación/comprensión esencialmente histórico, es decir, vinculado estructuralmente a la propia historia de la filosofía. 
En esta escueta referencia a Heidegger encontramos una cierta similitud con las exigencias al pensar teológico que Congar, entre otros, hacía en la época conciliar. La similitud, a nuestro juicio, estriba en la radicalidad de un pensar que quiere llegar, a través de conceptos e ideas, al fenómeno-acontecimiento mismo en toda su complejidad y vitalidad, en toda su "actualidad", y no solo "acumular" datos; es decir, un modo de pensar distinto a la teología conceptualista, en la que, según Congar, "cada cosa está definida de tal forma, que no queda ningún aspecto sin precisar"; y continua diciendo, "cada realidad es objeto de cierto número de 'tesis' o proposiciones, cuyo conjunto forma la 'doctrina'. Esta está formada por la suma de tesis que se han ido estableciendo sucesivamente, o de afirmaciones fijadas y como depositadas en fórmulas estándar situadas ante el espíritu, como objetos o cosas. Estas afirmaciones y estas tesis dan la impresión de ser algo así como artículos en un código, clasificados en diferentes capítulos. Dicha teología se enseña, se estudia, es una especie de lenguaje hecho de palabras que traducen conceptos" (9).

Así pues nos queremos acercar al concilio no como una colección de documentos del pasado sino como un fenómeno, un acontecimiento, que hoy me permite, a través de la hermenéutica, descubrir en él "indicaciones formales" que me otorgan la oportunidad de releer mi mundo como historia y "signo de los tiempos" desde la perspectiva del Evangelio (10). A continuación hay que resolver, aunque solo sea provisoriamente, la problemática de la hermenéutica de las declaraciones conciliares del Vaticano II.

\section{LA SIGNIFICACIÓN DEL EVENTO CONCILIAR CONVOCADO POR JUAN XXIII A LA LUZ DEL HORIZONTE MÁS AMPLIO DE LA HISTO- RIA DE LA IGLESIA: FRUTOS DE UN ANÁLISIS DE INTENTOS DE HERMENÉUTICA CONCILIAR}

La disputa acerca del significado del concilio estalló con particular virulencia inmediatamente después de su conclusión (11). De hecho, la minoría que ya durante

(9) Situaciones y tareas de la teología hoy, Salamanca 1970, 52; ver también M.-D. Chenu, El itinerario teológico, Ciencia Tomista (Homenaje al P. M.-D. Chenu) 112 (1985), 232.

(10) Cf. G. Wassilowsky, Die Chance des zweiten Blicks. Plädoyer für eine historische Konzilsforschung, Herder Korrespondenz 57 (2003), 623-627.

(11) A continuación se hará referencia a la pregunta por el significado del Concilio. Dentro de una literatura ya inabarcable, a modo de ejemplo cf. K. Wenzel, Kleine Geschichte des Zweiten Vatikanischen Konzils, Freiburg 2005; S. Wiedenhofer, Freiheit, Vatikanum II und moderne: eine fundamentaltheologische Reflexion, Freiheit und Katholizismus (1999), 71-96; F. Svidercoschi, Un Concilio che continua. Cronaca-Bilancio-Prospettive del Vaticano II, Milan 2002; R. Fisichella (ed.), Il Concilio Vaticano II. Recezione e attualità alla luce del Giubileo, Milán 2000; P. Hünermann (ed.), Das II Vatikanum. Christliche Glaube im Horizont globales Modernisierung, Paderborn 1998; N. Kutschki (ed.), Erinnerung an einen Aufbruch. Das II. Vatikanische Konzil, Würzburg 1995; S. Madrigal Terrazas, Memoria del Concilio. Diez evocaciones del Vaticano II, Bilbao 2005; id., Vaticano II: Remembranza y actualización. Esquema para una eclesiología, Santander 2002; O.-H. Pesch., Das Zweite Vatikanische Konzil. Vorgeschichte-Verlauf-Ergebnisse-Nachgeschichte, Würzburg ${ }^{3} 1994 ;$ G. Wassilowsky (ed.), Zweites Vatikanum-vergessene Anstöße, gegenwärtige Fortschreibungen, Friburgo-Basilea-Viena 2004; G. Routhier, Recherches et publications récentes autour de Vatican II, Laval théologique et philosophique 60 (2004), 561677 (el autor remite en la primera nota de esta crónica a otras que ha venido realizando en la misma revista desde 1997). Interesante resultan los números monográficos de las revistas Mün- 
los trabajos del concilio se había opuesto a la retoma de la gran tradición de la Iglesia (es decir, de una tradición que no podía quedar reducida a los pronunciamientos magisteriales de los últimos dos siglos y que era mucho más variada en su realidad interior que cuanto pretendía el revestimiento neoescolástico que se le había impuesto a partir de la segunda mitad del siglo XIX) y del aggiornamento y del "nuevo pentecostés" en el sentido querido por el papa Juan XXIII (12), planteó su rechazo del concilio sobre la tesis del error (13). Según esta, el concilio fue una traición a la tradición católica postridentina, tanto con sus innovaciones litúrgicas como con las doctrinales (Escritura y Tradición, colegialidad, etc.) y con su apertura a la cultura secularizada tal como se había expresado sobre todo en la Constitución Gaudium et spes (14).

La "revolución" juvenil de 1968 en los Estados Unidos y Europa occidental agudizó el conflicto de las interpretaciones. En aquel clima que auspiciaba la "imaginación al poder" y el "final a las interpretaciones" (Susan Sontag), se sostenía que el concilio había cerrado definitivamente una época, con lo que representaba, por decirlo así, un "corte” en la tradición de la Iglesia. El eslogan, en sí mismo justificado, de "el final de la Contrarreforma" se vio cargado de un significado exagerado, hasta hacer del Vaticano II un acontecimiento perteneciente como tal al pasado eurocéntrico.

Entre integrismo y contestación "progresista", algún otro invocaba el retorno a los "documentos" como antídoto frente a cuantos pretendían actuar basándose en el "espíritu" del concilio". Otros más, en su intento de llevar de nuevo el concilio al interior de los límites tradicionales de la hermenéutica teológica, han recordado la exigencia de interpretarlo en la continuidad de la realidad católica.

chener Theologische Zeitschrift 56 (2003), Asprensas 50 (2003), Scuola Cattolica 133 (2005) y Gregorianum 86 (2005) dedicadas al Concilio Vaticano II. Desde la perspectiva de la teología latinoamericana resultan sugerentes las reflexiones de $\mathrm{R}$. Muñoz, La recepción de la Lumen Gentium en América Latina. A los cuarenta años de su promulgación, Revista Latinoamericana de Teología 63 (2004), 267-283; la revista "Alternativa" (Managua) 9 (2002) es un interesante balance del Vaticano II; la revista Vida Pastoral 243 (2005) contiene asimismo un buen balance de los cuarenta años del concilio, en especial el artículo de J. B. Libanio (23-30); C. Schickendantz, Cambio estructural en la Iglesia. Ilustrativas resultan las reflexiones contenidas en la obra editada por R. Gibellini sobre las perspectivas teológicas para el siglo XXI, pues analizan el Concilio en su carácter prospectivo, Prospettive theologiche per il XXI secolo, Brescia 2003.

(12) Vale recordar las palabras de Juan XXIII: "Renueva en nuestros tiempo tus prodigios como en un nuevo pentecostés, y concede que tu Santa Iglesia, preservando más unánime e insistentemente en la oración junto a María, Madre de Jesús, y conducida por san Pedro, propague el reino del Salvador divino, reino de verdad y de justicia, reino de amor y de paz". Pablo VI, al evaluar catorce años después esta intuición, la califica de "profética", y puso en relación mutua la nueva experiencia del Espíritu con la magnitud de los problemas y horizontes humanos frente a los que la Iglesia necesita responder, fortificada e impulsada por una nueva efusión del Don de Dios: "No es que Pentecostés haya cesado alguna vez de ser actual en el curso de la historia de la Iglesia, pero son tan grandes las necesidades y peligros de este siglo, tan vastos los horizontes de una humanidad enderezada a la coexistencia mundial, pero impotente de realizarla, que para ella no hay salvación sino en una nueva efusión del Don de Dios. ¡Venga pues el Espíritu Creador a renovar la faz de la tierra!" (Exhortación apostólica Gaudate in Domino, Acta Apostolicae Sedis [AAS] 67 [1975], 317). En adelante se harán referencias a la importancia de Juan XXIII para y en el Concilio, cf. Alberigo, Critères, 268ss; ver el número especial de la revista Cristianesimo nella storia 2 (2004) dedicado a Juan XXIII.

(13) Cf. D. Menozzi, L'anticoncilio (1966-1984), en: Il Vaticano II e la Chiesa, Brescia 1985, 433-464.

(14) Cf. O.-H. Pesch, Das Zweite, 141ss; H.-J. Sander, Die pastorale, 185-206. 
En este último punto aparece, a mi juicio, una de las interrogantes más sugerentes con respecto al concilio y que analizaremos sucintamente en el próximo punto: ¿la exigencia de interpretar el concilio en la continuidad de la realidad católica, a pesar de ser justa, no conllevará un cierto peligro de restar originalidad, o si se quiere, de no hacerse del todo cargo del momento de "discontinuidad", de nuevo "paradigma", del acontecimiento (15) mismo? Por eso la pregunta que nos planteamos a continuación es la siguiente: ¿la originalidad del concilio hay que entenderla al interior de la continuidad o como un cambio de "paradigma" (Thomas Kuhn), en donde aquella es asumida en una nueva síntesis? (16).

En un sugerente y contundente ensayo, W. Kasper ha realizado una hermenéutica de las declaraciones conciliares (17), que en cuatro puntos se pueden sintetizar de la siguiente manera: 1. Hay que tener en cuenta la tensión interna entre las afirmaciones conciliares y sus respectivas tradiciones; por eso no es procedente ni resolver esta tensión unilateralmente ni dejarla en una yuxtaposición permanentemente abierta; la tensión pide una correcta integración. 2. La letra y el espíritu de concilio deben aclararse e interpretarse recíprocamente. Cada afirmación debe entenderse desde el espíritu del conjunto y este a su vez desde los distintos enunciados (el "círculo hermenéutico" como principio básico de la hermenéutica textual). El "espíritu" del concilio es, evidentemente, la voluntad de renovación de la Iglesia y de la fe, preservando toda la tradición bíblica y patrística, parcialmente olvidada, por una parte, y atendiendo mejor, por otra, los retos históricos actuales de la fe. El concilio no quiso "limitarse a repetir la tradición, sino actualizarla e interpretarla en forma viva de cara a la nueva situación. No buscó una nueva doctrina sino una renovación de la antigua" (Pottmeyer). Y exactamente este uso de la tradición renovador y actualizador, que integra la situación moderna de la fe en la enseñanza dogmático-pastoral, constituye el empeño específico del concilio, sin necesidad de definir para ello nuevos dogmas. 3. El concilio Vaticano II debe interpretarse en el horizonte y en el sentido de la tradición eclesial completa, sobre todo de las grandes verdades trinitarias y cristológicas de los primeros siglos. No es correcto abordarlo aisladamente, perdiendo de vista la continuidad del proceso de tradición eclesial.

(15) Aquí utilizamos la palabra acontecimiento en el sentido "filosófico" (en el sentido del "Ereignis"), que a mi modo de ver le otorgan por ejemplo P. Hünermann, J.-H- Tück, K. Lehmann y G. Alberigo (Alberigo ha notado como la palabra événement en Chenu y otros pensadores franceses no indica solo lo que acaece sino que aquello que acaece reviste una importancia para el hombre [La teologia dei, 49, nota 56; cf. P. Vallin, Vatican II, l'événement des historiens, Rescherches de science religieuse 93 [2005], 215-245). Como lo ha subrayado Lehmann a propósito de la hermenéutica del Vaticano II, en analogía a otros fenómenos similares, este concilio debe ser entendido como "acontecimiento" (Ereignis) y no como una simple ordenación de documentos (cf. Hermeneutik, 74).

(16) Además de la bibliografía aludida supra en la nota 11, cf. especialmente, K. Lehmann, Hermeneutik für einen künftigen Umgang mit dem Konzil, en: G. Wassilowski (ed.), Zweites Vatikanum, 71-89; G. Wassilowski, K. Rahners, en ibid., 49ss; G. Alberigo, Critères herméneutiques pour une historie de Vatican II, en: J.-P. Jossua/N.-J. Séd (eds.), Interpréter (Mélanges offerts à C. Geffré), Paris 1992, 261-275; id., Fedeltà e creatività nella recezione del concilio Vaticano II. Criteri ermeneutici, Cristianesimo nella storia 21 (2000), 383-402; C. Scanzillo, La recezione dell'ecclesiologia del Concilio Vaticano II, Asprensas 44 (1997), 323-344; A. Marchetto, Das Zweite Vatikanische Konzil. Hermeneutische Tendenzen von 1990 bis heute, Annuarium Historiae Conciliorum 32 (2000), 371-386; A. Auterio (ed.), Herausforderung-Aggiornamento. Zur Rezeption des Zweites Vatikanischen Konzils, Altenberge 2000. 
Pero tampoco es procedente reajustar el concilio a la tradición de los últimos siglos hasta perder su fuerza renovadora, que relativiza precisamente esa tradición en sus grandes unilateralidades y la integra de nuevo en la totalidad de la tradición bíblica y eclesial. 4. Los textos del concilio deben leerse e interpretarse en el horizonte de los signos del tiempo actual, de la situación de la fe hoy, porque no pretenden conservar a modo de archivo determinadas verdades sino servir a la fuerza persuasiva actual y futura de la fe.

A pesar de lo iluminador de las ideas recién señaladas, creemos, sin embargo, que Kasper no ha subrayado del todo el momento de la novedad (18), el "momento de inflexión" (19), de la originalidad que supuso el Vaticano II. Este momento, ha sido, a nuestro juicio, profundamente desarrollado por P. Hünermann, que, sin dejar de referirse a la continuidad del concilio en el marco de la historia de la Iglesia, ha sabido descubrir el carácter "paradigmático" de aquel (20).

Aquí somos, por cierto, conscientes de las advertencias hechas por J.-H. Tück (21) y G. Wassilowsky (22) en cuanto a que todavía queda mucho camino científico por recorrer para poder precisar de modo definitivo el momento de continuidad y discontinuidad que supone el concilio en su "carácter de proceso" (Lehmann) en relación al estatuto epistemológico de la tradición de los concilios precedentes, y que en ningún caso la problemática se puede traducir a una simple elección o "alternativa" entre continuidad y discontinuidad, pues como subraya Tück, "no hay aggiornamento sin ressourcement" (23); sin embargo, pensamos que los ensayos de Hünermann, quien tiene en cuenta sobre todo la última advertencia, ha notado la importancia de subrayar el momento de discontinuidad, de paradigma del concilio, sobre todo en el ámbito de cómo se deben "razonar" las relaciones entre los diversos contenidos de la fe y la teología.

A partir de las modernas teorías de la ciencia, Hünermann ve cómo estas han llamado la atención sobre estructuras fundamentales en las cuales se realizan las formaciones de teorías científicas y los procesos de trabajo. Un momento central en

(17) Cf. El desafío permanente del Vaticano II. Hermenéutica de las aseveraciones del concilio, en: íd., Teología e Iglesia, Barcelona 1989, 401-415.

(18) En el mismo sentido P. Henrici, Das Heranreifen des Konzils. Erlebte Vorkonzilstheologie, Internationale katholische Zeitschrift Communio 19 (1990), 482-496, 482-492, subraya más el momento de la continuidad que el de la discontinuidad.

(19) Cf. P. Neuner, Ekklesiologie, en: W. Beinert, (ed.), Glaubenszugänge. Lehrbuch der katholischen Dogmatik, vol. 2, Paderborn 1995, 407-408.

(20) Cf. las siguientes contribuciones de Hünermann: Konkretion und Geist, 216-227; Deutsche Theologie auf dem Zweiten Vatikanum, en: W. Geerlings/M. Seckler (eds.), Kirche Sein (Für H.J. Pottmeyer), Friburgo 1994, 141-162; Das II Vatikanum als Ereignis und die Frage nach seiner Pragmatik, en: íd., (ed.), Christlicher Glaube im Horizont globaler Modernizierung, Paderborn 1998, 107-126, interesante resulta al inicio de esta contribución el diálogo con Kasper (hay traducción al italiano en Il Regno 11 [1997]); Die neue Begrifflichkeit in der Ekklesiologie des II. Vatikanums, en: íd., Ekklesiologie im Präsens. Perspektiven, Münster 1995, 38-54; Lumen Gentium (kommentiert von Peter Hünermann), en: P. Hünermann/B. J. Hilberath (eds.), Herders Theologische Kommentar zum Zweiten Vatikanischen Konzil, vol. 2, Friburgo-Basilea-Viena 2004, 263-582; Il Concilio Vaticano II: Svolta della teologia del XX secolo, en: G. Canobbio (ed.), Associazione Teologica Italiana. Teologia e storia: l'eredità del '900, Milan 2002, 325-347.

(21) 40 Jahre, 48-59.

(22) Universales Heilssakramet Kirche. Karl Rahners Beitrag zur Ekklesiologie des II. Vatikanums, Innsbruck 2001, 16-37

(23) 40 Jahre, 59. 
los procesos de innovación científica lo constituye la formulación de nuevos "paradigmas", lo cual conlleva a nuevas perspectivas para la organización y ordenamiento de fenómenos con respecto a la visión anterior, lo que abre la posibilidad de nuevas visiones y con ello nuevas soluciones que hasta antes constituían aporías. Un segundo momento importante lo constituye la comunidad científica, la Scientific Community, que a través de la recepción de nuevos "paradigmas" (Kuhn, Wittgenstein), prioridades, esquemas de ordenamiento, dirección de las preguntas y valoraciones se revierten y con ello las investigaciones científicas adquieren un nuevo rostro. Con ello se posibilita que en el proceso de recepción a través de la "comunidad científica" se den desconocidas posibilidades para la formación de nuevas teorías como asimismo nuevos conocimientos de distintas áreas del saber.

La formación de nuevos paradigmas conlleva y funda un juego de lenguaje específico en el sentido de Wittgenstein. A propósito del Vaticano II, Hünermann se pregunta hasta qué punto sus intuiciones fundamentales nos dan la chance para hablar de un "cambio de paradigma", de un proceso de innovación en contraste con la neoescolástica.

Si se reflexiona sobre los textos del Vaticano II a la luz de la teología de escuela neoescolástica, este contraste revela una "intuición formal fundamental", que se puede caracterizar, según Hünermann, de la siguiente manera: "la teología está ordenada a conceptos estructurales de la razón (vernünftige Strukturbegriffe), no a conceptos reflexivos del entendimiento (verstandesmäßige Reflexionsbegriffe)" (24).

Para explicar los términos "conceptos estructurales de la razón” y "conceptos reflexivos del entendimiento" Hünermann toma de ejemplos textos del Concilio Vaticano II y de la "teología de escuela" ("Schultheologie") previa al concilio (25).

En la "teología escolar" preconciliar se plantea repetidamente la pregunta por la relación entre la Iglesia y el Reino de Dios, en donde se establece una diferencia entre ambas realidades. La existencia de la Iglesia es finita. Un representante de la "Schultheologie" como Zapelena, establece: "La condición celestial no pertenece a la Iglesia jerárquica y luchadora, fundada sobre Pedro por Cristo". "En un cierto sentido" -en latín: quodammodo- existe, sin embargo, una identidad entre la Iglesia y el Reino de Dios. Según Hünermann, el aspecto en el cual se da tal solapamiento es indicado con precisión. Schmaus afirma al respecto: "Sin embargo, se puede hablar en cierto sentido de la existencia posterior de la Iglesia transformada" ("en el cielo" agrega Hünermann), en tanto se entienda por Iglesia la comunidad de los hombres convocados por Cristo en el Espíritu Santo y conducidos ante el Padre". Leyendo los textos citados se puede advertir qué tipo de conceptualidad prevalece. Hünermann llama la atención como aquí se determinan diferentes "contenidos" ("Was-Gehalte") de la Iglesia. Cada uno de esos contenidos es mantenido en sí, en una autorreferencia. En este sentido se puede hablar de una "determinación reflexiva" ("Reflexionbestimmung"): esto concierne al estado de cosas particular en tanto concepto objetivo de reflexión. El contenido particular está en sí. A él le correspon-

(24) Duetsche Theologie, 144.

(25) Para las citas de T. Zapelana y M. Schmaus cf. P. Hünermann, Konkretion und Geist, 216-227. 
de el acto subjetivo de la reflexión. Un aspecto general del estado de cosas en cuestión, en este caso la Iglesia, es destacado, separado de los restantes aspectos, establecido y fijado. A esto le sigue el próximo paso apunta Hünermann: se debe decidir cuál de los contenidos fijados de modo abstracto debe valer directamente para la Iglesia. Los contenidos restantes valen solo limitadamente. La relación de ambos contenidos es puesta en una relación exterior, pues ambos contenidos son establecidos como conceptos de reflexión. De este modo Schmaus caracteriza la ecclesia vissibilis como órgano o bien instrumento, el cual debe mediar entre la comunidad y Cristo. A este tipo de "conceptos reflexivos del entendimiento", tal como se pueden encontrar en la teología neoescolástica, se le opone la formación de "conceptos estructurales de la razón", como aparece en enunciados a lo largo del Concilio Vaticano II, aunque no de modo totalmente exclusivo. Como ejemplo de ello valga un texto en el que la relación entre la Iglesia visible y el invisible Reino de Cristo y de Dios es tematizada en la Constitución Dogmática sobre la Iglesia Lumen Gentium: "Cristo, el único mediador, estableció en este mundo su Iglesia santa, comunidad de fe, esperanza y amor, como un organismo visible. La mantiene así sin cesar para comunicar por medio de ella a todos la verdad y la gracia. Pero la sociedad dotada de órganos jerárquicos y el cuerpo místico de Cristo, el grupo visible y la comunidad espiritual, la Iglesia de la tierra y la Iglesia llena de bienes del cielo, no son dos realidades distintas. Forman más bien una realidad compleja en la que están unidos el elemento divino y el humano" (26).

En este breve párrafo se caracteriza cuatro veces y en distintos giros a la Iglesia como comunidad con Cristo y cuatro veces como Iglesia visible. Ambos aspectos son vinculados en cada caso con un "y". Aún más: al final del texto se expresa su identidad. Los contenidos establecidos en la teología neoescolástica aparecen aquí en su diferenciabilidad también mencionados y respetados. Pero no son fijados en una autorreferencia ni puestos en relaciones externas. Más bien se enuncia la unidad de lo diferenciado. Su unidad es caracterizada como interna. Así aparece la figura histórica de la Iglesia como aquella forma en la que Jesucristo eleva la comunidad con el hombre, y a la inversa, los miembros de la Iglesia visible son comienzo y desarrollo del Reino de Dios. Los diferentes contenidos son vistos en una unidad que se constata y acredita mutuamente. Su conexión es considerada estructuralmente, es decir, los diversos contenidos forman, en cuanto momentos, una unidad en tensión, en la cual los momentos particulares se determinan recíprocamente, efectuando cada uno por medio del otro. Aquí la autorreferencia se da

(26) Lumen Gentium 8 (DH 4118); cf. P. Hünermann, Lumen Gentium (kommentiert von Peter Hünermann), 365-372. Hunermann hace notar que la concepción efectiva de una Iglesia universal es posible por el paso desde una "conceptualización" (Begrifflichkeit) de reflexión en la que las diferencias se remitían a la determinación de una definición esencial (Reflexionsbestimmung) abstracta y previa (de modo que aquellas resultaban, al menos tendencialmente, subsumidas y eliminadas), hacia una de tipo especulativo ("spekulative Begrifflichkeit") que afirma las diferencias concretas e históricas y las capta unidas y relacionadas para conformar un todo. En el caso de la eclesiología del Vaticano II se puede citar por ejemplo el Lumen Gentium 8 donde las dimensiones visible e invisible de la Iglesia son afirmadas en mutua necesidad y en su propia naturaleza, pero no se absorben ni se eliminan, sino que se reconocen como elemento divino y humano que forman parte de "una realidad compleja" (cf. ibíd.; Konkretion und Geist, 216-227, sobre todo 216-220). 
solamente como referencia al otro ("Selbstbezüglichkeit gibt es hier nur als Fremdbezüglichkeit"). Como en muchos de sus contribuciones aquí se puede rastrear la influencia del filósofo alemán H. Rombach en Hünermann quien a través del desarrollo de lo que se podría denominar una filosofía de la "estructura" ha señalado el cambio que se ha producido en la modernidad en relación al concepto de sustancia como central para explicar lo que las cosas sean, indicando que a este concepto le sucede -dialécticamente- el de "sistema" y en la actualidad el de "estructura" (27).

El ejemplo consignado es completado por Hünermann mediante numerosos otros. Así el modo cómo en la Encíclica Qui pluribus de Pío IX se entiende inmediatamente a la Revelación como el hablar de Dios, que es confirmado por la vida y obra, muerte y resurrección de Jesucristo. En este caso el contenido, la Revelación, es concebida como un estado de cosas permanente. El acontecer cristológico es ordenado exteriormente respecto a ella (28). Si se compara esto con los enunciados del Concilio Vaticano II, salta a la vista la diferencia: en Dei verbum Jesucristo, él mismo, en vista a su presente, su anuncio, sus palabras y obras, signos y milagros, muerte y resurrección, es caracterizado como la revelación de Dios.

La transformación del tipo de concepto es una cuestión altamente significativa. Los conceptos son aquellas formas que garantizan el pensamiento de una multiplicidad que se muestra. Si resulta un nuevo tipo de conceptualidad, entonces la multiplicidad de momentos se muestra a la vez en otros nexos, nacen nuevos nexos de significación. No es pues ningún milagro que la intuición formal fundamental se concretice en intuiciones fundamentales conductoras teológicas, es decir, de contenido. La primera se refiere a Dios y a la relación procedente de él hacia los hombres, la historia y el mundo. La segunda intuición fundamental se refiere a la relación de Jesucristo hacia la Iglesia y los hombres. La tercera intuición fundamental se refiere a la Iglesia y a los creyentes, por una parte, y a las relaciones mundanas e históricas en que estos viven, por otra. Estas tres intuiciones fundamentales están en un nexo teológico íntimo.

Esta breve presentación de las ideas de Hünermann nos conduce a un tipo de quehacer teológico que no piensa lo otro de lo trascendente o lo eclesial en el sentido neoescolástico que entendía los contenidos teológico-eclesiales primero tenían una subsistencia en sí mismos y que solo después de esta constatación se relacionaban con otros temas mal llamados extrateológicos, sino que aspectos tan relevantes del concilio como la historia o los signos de los tiempos que en ella se revelan pasan a ser un tema ineludible a la hora de interpretar la propia revelación y

(27) El concepto de estructura se ha obtenido del organismo viviente (así ya Kant: estructura es "disposición y combinación de las partes de un organismo que se forma de acuerdo con un fin unitario") y como tal es una categoría fundamentalmente dinámica, que sobre todo encierra la posibilidad de crecimiento ("progreso"), a diferencia del sistema cerrado. Según Rombach, se pueden formular cinco principios de una teoría filosófica de la estructura: 1. la estructura es un sistema abierto; 2. la teoría de la estructura es dinámica; 3. la estructura es mismidad y referencia a otro (Selbstheit und Andersheit); 4. la teoría de la estructura es una filosofía de la concreción; 5. la teoría de la estructura es fenomenológica. En ella se entiende la estructura sobre todo como un fenómeno opuesto a substancia, que se distingue por la consistencia propia y la determinación interna, mientras que la estructura solo se articula a sí misma delimitándose frente a otra cosa. La estructura no se puede, por tanto, definir ya en el sentido clásico (Substanz-System-Struktur, vols. 1-2, Friburgo 1965-66).

(28) Cf. DH 2778s. 
el ser y misión de la Iglesia. Brevemente: se abre la posibilidad de integrar al quehacer teológico la forma de razonar de "identidad y diferencia".

Esta simple enumeración de algunas de las interpretaciones del Vaticano II presentes en la Iglesia católica -y sería preciso recordar también, al menos, la ofrecida por el Sínodo de los obispos de 1985 (29)- y el habernos detenido en la problemática de su carácter de paradigma a propósito de los análisis de $\mathrm{P}$. Hünermann, muestra ya por sí sola la necesidad de una reconstrucción histórica del acontecimiento conciliar. Por lo demás, dicha reconstrucción ya se ha iniciado (30). Nosotros solo vamos a desarrollar aquí tres puntos que revisten un especial interés metodológico. El primero (3), que intenta captar algunos elementos del "espíritu" del acontecimiento conciliar, recoge ya algunas indicaciones de la investigación histórica sobre el último concilio; el segundo (4), que intenta situar el viraje decisivo conciliar en el camino de la tradición eclesial, se remite a una conocida hipótesis interpretativa de Karl Rahner; el tercero (5), finalmente, quiere proponer algunas observaciones hermenéuticas sobre los "signos de los tiempos", indicación metodológica verdaderamente fundamental del Vaticano II.

\section{DE LA REFORMA AL AGGIORNAMENTO: DISCERNIMIENTO DEL ESPÍ- RITU CONCILIAR}

El Vaticano II representa una novedad respecto al pasado, pero no en el sentido de que haga caso omiso de la tradición. Más bien se puede afirmar tranquilamente que es, respecto a la tradición de la Iglesia, mucho más respetuoso que, por ejemplo, el Vaticano I (31). De hecho, en el Vaticano II actuó, respecto al concilio de 1870 , una voluntad de ressourcemento (32), como lo expresa un testigo y destacado teólogo como G. Martelet, "Jaillissement renouvelé ou Résurgence des Sources” (33). Se trata, según G. Thils, de una triple "repristinación": bíblica, patrística, litúrgica, a la que habría que añadir, en el espíritu de la teología francesa renovada de la época anterior al concilio, tomista y medieval. Esto es, el deseo de llegar de nuevo a las fuentes antiguas de la vida de la Iglesia sin limitarse a los desarrollos de los últimos ciento cincuenta años, lo cual es justamente lo contrario de una mentalidad temerosa de la vastedad de la tradición global de la Iglesia que prefiere no modificar el equilibrio tranquilo y limitado del pasado próximo.

(29) Cf. W. Kasper, Zukunft aus der Kraft des Konzils. Die ausserordentliche Bischofssynode 85, Friburgo 1986.

(30) Cf. la monumental historia del concilio que ha sido dirigida y llevada cabo por G. Alberigo, ya completa en italiano en cinco volúmenes, Storia del concilio Vaticano II, Bologna 1995-2001, que en español va, hasta donde tenemos conocimiento, en el segundo volumen (editada por Sígueme); un resumen en íd., Historia de los concilios ecuménicos, Salamanca 1993, 335-374.

(31) Cf. G. Alberigo, Die Rezeption der großen christlichen Überlieferung durch das zweite Vatikanische Konzil, en: W. Löser/K. Lehmann et al. (eds.), Dogmengeschichte und katholische Theologie, Würzburg 1985, 303-320.

(32) Cf. G. Thils, Orientaciones actuales de la teología, Buenos Aires, 1959. El neologismo "repristinación" nos parece apropiado para traducir el francés "ressourcement", que estaría así en el mismo campo semántico que "aggiornamiento"; cf. el uso del término "ressourcement", en $Y$. Congar, en: S. Madrigal Terrazas, Memoria, 44ss.

(33) Les idées maîtresses de Vatican II, París 1969, 9ss. 
La novedad principal del Vaticano II la constituye más bien la consideración misma de la historia en su relación con el Evangelio y la verdad cristiana (34). Es más, se puede decir que el mismo Melchor Cano presenta con sus loci "la estructura de una mediación histórica de la verdad de la fe" ("die Struktur einer geschichtlichen Wahrheitsvermittlung des Glaubens") (35). Los diferentes Topoi no son deducibles sistemáticamente. Sin embargo, se originan desde la lógica de la fe cristiana en la historia y le otorgan desde allí a la teología su "armazón" (36).

\subsection{Dos antecedentes en el intento de recuperación de la historia como tema teológico: la “Escuela de Tubinga” y el aporte de M.-D. Chenu (37)}

Como bien lo ha señalado G. Angelini, la renovación teológica que posibilita el concilio se da sobre todo en dos países: Francia y Alemania. El primero, casi hegemónico en la primera mitad del siglo, a diferencia de la teología alemana que aparece más bien en los años cuarenta con toda su fuerza, no se basa tanto en el diálogo con filosofía moderna, como en una vuelta a las fuentes patrísticas y medievales, y una especial sensibilidad para con la cultura y cambios de la época decimonónica al siglo $\mathrm{XX}$ industrial y protocapitalista. A continuación desarrollaremos una breve presentación de cómo en estos dos ámbitos se da una renovada -aunque a veces a esto se llega por caminos diversos- valoración de la "historia" como tema inherente al quehacer teológico y que, a nuestro juicio, está a la base de la renovación que con respecto a este tema supondrá el concilio, y que se constituye en el humus que permitirá una relectura de la teología de los "signos de los tiempos" que, como hemos dicho, se puede considerar uno de los aportes claves del concilio a la teología.

3.1.1 La historia reflexionada desde la historicidad como aspecto esencial de la teología. El aporte de M.-D. Chenu a un tema fundamental del Vaticano II (38).

Son muchos los teólogos y pensadores franceses que en las décadas anteriores al concilio abonaron la reflexión sobre el rol fundamental de la historia para la

(34) Cf. los agudos análisis de J. Noemi al respecto en El mundo. Creación y promesa de Dios, Santiago 1996, 228ss.

(35) P. Hünermann, Neue Loci theologici, 5 .

(36) Cf. ibíd.

(37) Cf. para una panorámica, A. Angelini, art. Historia-historicidad, en: L. Pacomio et al (ed.), Diccionario Teológico Interdisciplinar, vol. 3, Salamanca 1982, sobre todo $57 \mathrm{ss}$; G. Cannobio, Uno sguardo complessivo sulla teologia del '900, en: id., Teologia, 7-32; R. Schaeffler et al., art. Geschichte, Geschichtlichkeit, en: W. Kasper (ed.), Lexikon für Theologie und Kirche, vol. 4, Friburgo ${ }^{3} 1995$, 553-564; G. Essen, Geschichte als Sinnproblem. Zum Verhältnis von Theologie und Historik, Theologie und Philosophie 71 (1996), 321-333; G. Ruggieri, La storia come luogo teologico, Laurentianum 35 (1994), 319-337; D. Henrici, Das Heranreifen, 482-496 (con especial cuidado en subrayar el aporte de las líneas francesas y alemanas de recuperación de lo histórico y la historicidad para la teología). Desde el punto de vista filosófico resultan sugerentes los planteos de M. Illescas, La temporalidad como irrenunciable dimensión de lo humano, Revista de filosofía (Universidad Iberoamericana/México) 86 (1996), 244-282.

(38) Cf. las pertinentes reflexiones sobre Chenu en, E. Silva, Marie-Dominique Chenu: un teólogo de los signos de los tiempos, en: AAVV, Grandes teólogos del Siglo XX, Santiago 1996, 115-150; íd., La significación teológica de los acontecimientos. El estatuto histórico de la teología según Marie-Dominique Chenu, Teología y Vida 33 (1992), 269-279. 
teología y la conciencia eclesial. De entre estos nos remitiremos a Chenu, por representar, a nuestro juicio, muy bien el espíritu de aquella generación.

La dimensión histórica y temporal se plantean como un reto que implica un redescubrimiento y por ende un replanteo de la teología, en la medida que, según señala este teólogo dominico, es un desafío a la conciencia contemporánea en general, una dimensión fundamental del hombre en particular y, por tanto, un elemento clave en la comprensión de la revelación misma: “... el tiempo, lejos de hacer que las cosas se marchiten, entra en composición con la vida del espíritu y en la inteligencia de las cosas; la historicidad es una dimensión esencial del hombre; y si tomo en consideración al hombre cristiano, la fe tiene por objeto y por fuente permanentes una economía de salvación inscrita en la historia” (39).

Chenu señala que la indiscutible grandeza del siglo XX consiste en haber integrado expresamente en el conocimiento del hombre la dimensión histórica, así, la historia "no es un aparato de erudición que sirve para conocer el pasado y que la cultura es portada por la memoria del pasado" (40). Se ha comprendido que la cultura no puede comprometerse con el futuro si ella rehúsa integrar el pasado. No nos ha de extrañar que Chenu y la escuela dominica de Le Saulchoir se sientan en continuidad con la "Escuela de Tubinga", sobre la cual hablaremos en el próximo punto, que en el siglo XIX introducía un principio de renovación de la teología con una concepción de la fe que integraba las dimensiones histórica, psicológica y pastoral (41). Chenu ha dicho que ha llegado a ser medievalista a partir de preocupaciones modernas, sintiéndose en vinculación con todo un movimiento cultural que, integrando la historia, hace de la dialéctica pasado-presente un principio de inteligibilidad (42).

El "sentido de la historia", ese sentimiento de que la humanidad está en marcha, es uno de los tres denominadores comunes de la mentalidad hodierna (43). Para el hombre contemporáneo, "el tiempo, realidad de la historia, no es un receptáculo amorfo e insignificante de unas acciones que lo mismo podrían ser instantáneas que eternas; por el contrario, tiene una trama, un sentido, una extensión dirigida, e. d., que su futuro, sus fines están ya presentes en cierto modo, confiriéndole el carácter de una esperanza, de una promesa, de una tensión mesiánica, por medio de la cual se halla siempre renovado y como más allá de sí mismo en una invención permanente" (44).

Por ello la referencia al tiempo no es una modalidad exterior a la verdad, sino que entra en el tejido mismo de la verdad. En síntesis, para Chenu, “el rasgo más significativo del hombre nuevo en la civilización moderna lo constituye la toma de conciencia de su ser-en-la-historia, así como de su ser-en-el-mundo" (45).

(39) Presentación de La Parole de Dieu, vol. 2, L'Evangile dans le Temps, Paris 1964, 7.

(40) Cf. J. Duquesne interroge le Père Chenu, un théologien en liberté, Paris 1975, 51; cf. Le devenir Social, en: Pour une Théologie du Travail, Paris 1955, 78.

(41) Cf. J. Duquesne interroge le Père Chenu, 55.

(42) Cf. ibíd., 51.

(43) Junto con "el dominio del hombre sobre la naturaleza" y el "fenómeno de la socialización del hombre".

(44) Le Devenir Social, 79-80.

(45) Présentation de Théologie de la Matière, Paris 1968, 9-10. 
La historicidad se constituye de esta manera en un rasgo antropológico básico. El hombre está en la historia, la historia es su obra, y es haciendo la historia como llega a ser él mismo. Esta dimensión histórica del hombre tiene para Chenu su fundamento en la consustancialidad del alma y del cuerpo defendida por la antropología tomista: "Última propiedad del hombre, la historicidad. La historia es una dimensión del ser mismo del espíritu encarnado (...) Tiempo y lugar son coordenadas consustanciales del hombre. ¿Qué sería una humanidad que no tuviera geografía ni historia? El hombre, ser social, es por lo mismo histórico. Ambas propiedades son esenciales, porque la corporeidad es constitutiva del ser humano. La historia, ciertamente, sigue siendo obra de las personas, y la libertad es a la vez la fuente de todo valor y el principio de toda perfección. Pero esta libertad no procura valor y perfección en un más allá de la historia, en que la materialidad del tiempo sería solo el soporte inerte y ocasional de la relación puramente personal entre las conciencias. Todas las causalidades, incluso las materiales, del cuerpo y del cosmos están integradas en el tejido humano, en que el alma da sentido y continuidad a la fragilidad de los instantes" (46).

El cristiano, lejos de ver en esta emergencia de lo histórico un peligro que pone en cuestión su fe (47), ve aquí una feliz coincidencia, un mutuo enriquecimiento, una magnifica oportunidad, "si es cierto que el cristianismo no es una metafísica sagrada, en la intemporalidad platónica de una contemplación, sino una 'economía' en la historia. Dios ha venido en la historia..., y la historia es sustancialmente transformada. La historia entra en la construcción del Reino de Dios" (48). Es la convicción de que la "economía" es a la vez misterio e historia: el misterio en la historia y la historia en el misterio de Cristo. La nuestra es una religión de la historia, en contraposición con las religiones de la naturaleza, "una religión constituida por una economía de la salvación del hombre en la historia" (49). Como bien apunta el teólogo francés: "la economía judeocristiana es el ejemplo más eminente de una religión cuya fe fundamental es que la historia la conduce Dios, es la epifanía de Dios (...) Dios está implicado en el devenir histórico de Israel, y lo estará doblemente en el total devenir humano con el mesianismo de la Encarnación" (50).

Esto hace que el "sentido de la historia", algo fundamental para el pensar actual, coincida de cierta modo con la concepción del cristianismo, "cuyo misterio se revela en un hecho: el hecho de la Encarnación (...) en el que Dios se hace (...) un personaje de la historia" (51). De ahí que para Chenu el cristianismo "tenga una visión histórica del destino del mundo, ciertamente más allá de esta historia, pero con ella" (52).

(46) Spiritualisme et sociologie, en: La Parole de Dieu, vol. 2, L'Evangile dans le Temps, 443-444.

(47) Cf. M. Seckler, Das Heil in der Geschichte. Geschichstheologisches Denken bei Thomas von Aquin, Munich 1964.

(48) Présentation de Théologie, 9-10.

(49) Libération politique et messianisme religieux, en: La Parole de Dieu, vol. 2, L'Evangile dans le Temps 604.

(50) Un pueblo mesiánico, en: Los cristianos y la acción temporal, Barcelona 1968, 102.

(51) La Pensée contemporaine, en: La Parole de Dieu, vol. 2, L'Evangile dans le Temps, 182.

(52) Cf. ibíd., 620. 
Tenemos "una religión de la historia, en la que el pueblo humano, mediante la comunión con un Dios encarnado, realiza su destino colectivo"; una religión de la Palabra cuyo libro sagrado "no es una antología de preceptos ni un manual de ritos" sino "una historia en que el presente, alimentado por el pasado, está grávido de futuro"; una religión de la promesa en curso de realización y que se encarna progresivamente en el tiempo (53).

La reflexión crítica de esta religión, la teología que quiere ser inteligencia de la Palabra de Dios, inteligencia de la fe en acto en el curso del tiempo que está atenta a esta promesa, se ve desafiada y redefinida por esta historicidad que acabamos de analizar.

3.1.2 El redescubrimiento de la dimensión histórica del cristianismo en la "Escuela de Tubinga" (54)

En un sugerente estudio, P. Hünermann ha hecho referencia a cómo la teología alemana y en especial algunos destacados representantes de la "Escuela de Tubinga" ejercieron una influencia, aunque a veces indirecta, en muchos de los cambios más significativos que impulsó el Vaticano II (55). Por eso, en lo que viene a continuación, realizaremos una breve panorámica de cómo lo histórico se reintrodujo en el pensar teológico, subrayando de manera especial los ecos de la filosofía de Schelling (56) en estos pensadores (no es casualidad que algunos de los teólogos postconciliares que más han subrayado los cambios del concilio para la teología y la autocomprensión del cristianismo y la Iglesia a propósito de la recuperación del pensar histórico, siempre llamen la atención sobre el "ruido de fondo" que significa aquel filósofo alemán; baste para ello revisar lo expuesto por ejemplo por P. Hünermann, J. Noemi y W. Kasper (57).

De las reflexiones actuales sobre las relaciones entre historia y teología (58), se deduce que no puede concebirse la historia solo como mera acumulación de

(53) Cf.ibíd.

(54) Cf. P. Hünermann, Der Durchbruch geschichtlichen Denkens im 19. Jahrhundert, Friburgo 1967. Son útiles también para percibir el influjo de la teología alemana en el Vaticano II, H. Wolf (ed.), Die katholisch-theologischen Disciplinen in Deutschland 1870-1962. Ihre Geschichte, ihre Zeitbezug, Paderborn 1999; P. Hünermann/C. Arnold (eds.), Die deutschsprachigen Länder und das II. Vatikanum, Paderborn 2000.

(55) Deutsche Theologie, 141-162; Zeichen der Zeit, Theologische Quartalschrift 181 (2001), 275280; Hünermann también subraya los vasos comunicantes entre la "Escuela de Tubinga" y el Vaticano II en el art. Geschichte. In der Theologie, en: W. Kasper (ed.), Lexikon für Theologie und Kirche, vol. 4, Friburgo et al. ${ }^{3} 1995,562$; íd., Il Concilio Vaticano II: Svolta della teologia del XX secolo, 333ss. Ver también las valiosas observaciones que ofrece sobre las relaciones entre la "Escuela de Tubinga" y el Vaticano II W. Kasper, 'Vom Geist und Wesen des Katholizismus'. Bedeutung, Wirkungsgeschichte und Aktualität von J. S. Dreys und A. Möhlers Wesensbestimmung des Katholizismus, Theologische Quartalschrift 183 (2003), 196-212; G. Ruggieri, La storia, $324 \mathrm{ss}$.

(56) Cf. M. Seckler, Zur Struktur der Theologie und des Theologiestudiums. Die 'Kurze Einleitung in das Studium der Theologie' J. S. Dreys von 1819 als zukunftweisende enzyklopädische Programmschrift- Zugleich ein Beitrag zur Drey-Rezeption, Theologische Quartalschrift 182 (2002), 197-235, especialmente 209 y nota 37.

(57) Cf. A. Franz, Wozu Schelling? Aktuelle Schellings-Literatur aus theologischer Perspektive, Theologische Revue 98 (2002), 267-293, especialmente 287ss. 
hechos históricos, ni tampoco lo histórico en el cristianismo, como vieja documentación rancia, sino como un todo vital y como tradición, que a la vez es actualidad viva. La fe, que se remite esencialmente a Jesucristo, no solo posee ese Jesús terreno en el recuerdo subjetivo y por medio de la investigación histórica, sino también "objetivamente" como el Señor que pervive y sigue actuando en la Iglesia (59).

Este concepto orgánico de la historia significa la superación del método anterior, basado en los dicta probantia, y la división de la teología en sistemática y positiva. En la misma historia se da ya el sistema y las ideas tienen efectividad. En esta misma línea los tubinguenses toman del "método del studium académico" de Schelling, el método de la construcción histórica y filosófica del cristianismo (60). Consideran que hay que descubrir en la historia la idea única, que lo comprende y lo conforma todo, y captarla en su autodespliegue dialéctico. Como teólogos, ven en esa idea el plan eterno salvífico de Dios, que se realiza en la historia y llega a su plenitud en Jesucristo (61). Formulándolo de otra manera, hablan de la idea del reino de Dios, que lo comprende todo y se realiza históricamente (62). Como puede verse, en este enfoque el pensamiento histórico no solo determina la teología específicamente positiva, sino que lo peculiar de los teólogos tubinguenses consiste precisamente en que la misma teología especulativa es pensamiento histórico. Para estos teólogos la especulación no consiste en sacar conclusiones a partir de los resultados de la teología positiva o en cubrir desde fuera esos resultados con una metafísica o una filosofía trascendental, sino en unir racional e inteligiblemente los acontecimientos históricos con la idea única fundamental, formando un sistema orgánico que, apoyándonos en el lenguaje patrístico, podríamos denominar "filosofía del cristianismo".

Para Staudenmaier esta mediación dialéctica, concebida todavía más bien neoplatónicamente, consiste en una recapitulación creadora y espiritual, en una elaboración de la historia empírica a un nivel superior de reflexión (63).

Kuhn, que rechaza esta comprensión de la dialéctica, da, de acuerdo con el espíritu del idealismo alemán respecto al pensar histórico, un paso esencial: la dialéctica especulativa no es una mera recapitulación de la dialéctica histórica, sino su prolongación. La especulación, entendida en una forma tan totalmente histórica, considera el origen de la fe, refiriéndolo a su futuro posible y con ello a su comprensibilidad actual. Pero esto no se realiza como en Hegel por medio de la negación, de manera que todos los contenidos históricos concretos queden asumidos en la idea absoluta; la especulación teológica nunca puede abandonar su punto de partida his-

(58) Cf. J. Noemi, Esperanza en busca de Inteligencia. Atisbos teológicos, Santiago 2005; P. Hünermann, art. Geschichte; en este ámbito resulta muy sugerente volver a revisar el trabajo señero de M. Seckler, Das Heil in der Geschichte.

(59) Cf. J. S. Drey, Vom Geist and Wesen des Katholizismus, en: J. R. Geiselmann, Geist des Christentums und des Katholizismus, Mainz 1940, 196ss; íd., Die Apologetik als wissenschaftliche Nachweisung der Göttlichkeit des Christentums in seiner Erscheinung, vol. I, Mainz ${ }^{2} 1844$, 372ss; ver las observaciones de G. Essen, Geschichte als Sinnproblem, 333.

(60) Cf. Fr. W. J. Schelling, Vorlesungen über die Methode des akademischen Studiums (1802), en: Werke vol. III, München 1958, 308-327; cf. P. Hünermann; Zeichen der Zeit,, 276ss, quien muestra los vínculos entre este método, la "Escuela de Tubinga" y el Vaticano II.

(61) Cf. J. R. Geiselmann, Die katholische Tübinger Schule, Friburgo 1964, 280-346.

(62) Cf. Ibíd., 191-279; J. Rief, Reich Gottes and Gesellschaft nach J. S. Drey und J. B. Hirscher, Paderborn 1965

(63) Cf. Die christliche Dogmatik, vol. I, Friburgo 1844, 22, 112s. 144 s. 161. 169. 
tórico y pasar por encima de él; por eso, diferenciándose de Hegel, procede por el camino de la determinación y, a diferencia del método de abstracción de la escolástica, por el camino de la inducción, es decir, ascender lógicamente el entendimiento desde el conocimiento de los fenómenos, hechos o casos, a la ley o principio que virtualmente los contiene o que se efectúa en todos ellos uniformemente (64).

Enlazando críticamente con Hegel, Kuhn concibe la experiencia sensible como lo todavía indeterminado, como lo general que solo llega a constituirse en idea concreta mediante el pensamiento conceptual y su análisis crítico; en esa idea concreta se unen dialécticamente la unidad general de la idea y la multiplicación conceptual. La idea concreta última, que resume todo en sí, es la revelación del Dios uno en Jesucristo.

Una manera de pensar histórica, mantenida tan radicalmente, debía llevar en sus últimas consecuencias más allá de la tesis fundamental idealista, superando la concepción idealista de la identidad, que identifica libertad y necesidad, realidad (historia) y verdad, pensar y ser. Esta identidad idealista da primeramente la posibilidad intrínseca de una construcción filosófica de la historia. Pero si se rompe esa ambigüedad en favor de una visión claramente histórica, eso entraña a la vez consecuencias metodológicas. Por eso el mismo Möhler, orientado más histórica que especulativamente, apunta claras reservas contra la construcción filosófica (65). Reconoce que la forma de pensamiento propia del cristianismo es la historia y ve precisamente en eso la diferencia con la forma de pensar de la antigüedad pagana, que en este punto guarda un cierto parentesco con el idealismo de su tiempo (66). Para los antiguos el último principio es el destino, el fatum, la necesidad, mientras que en el cristianismo lo constituye la libre providencia histórica de Dios (67).

Sobre todo F. A. Staudenmaier recoge esta última idea en su época más tardía (68), especialmente al referirse a la filosofía de la última época de Schelling. Lo mismo que el Schelling más posterior, también Staudenmaier supera la identidad dialéctica de necesidad de la idea y libertad de la historia (69). Staudenmaier considera ahora la libertad de Dios como la medida única, verdadera y eterna, la última determinación y el principio de todo, siendo la condición básica y esencial del desenvolvimiento del reino divino. El cristianismo es el sistema de la libertad y personalidad divinas, que se manifiestan en hechos divinos. Hay que tener en cuenta que esta perspectiva, también metodológicamente, significa un paso decisivo más allá de Drey, que se mantuvo todavía totalmente ligado al pensamiento del idealismo avanzado. Staudenmaier considera ahora que todo conocimiento teológico es una

(64) Katholische Dogmatik, vol. I, Tübinguen ${ }^{2} 1859,242$ ss. Cf. lo dicho sobre la influencia de la fenomenología en el Vaticano II por E. Dulles, El oficio de la teología, Barcelona 2003, 105ss. 141 ss; ver el rol de la "inducción” en el Vaticano II en K. Lehmann, Hermeneutik, 82.

(65) Cf. J. A. MöhIer, discusión con A. Gengler, Über des Verhältnis der Theologie zur Philosophie, Landshut 1826, Theologische Quartalschrift 9 (1827), 515-517.

(66) Cf. J. Noemi, Esperanza en busca de Inteligencia, sobre todo 19ss.37ss.

(67) Cf. J. A. Möhler, Einleitung in die Kirchengeschichte, en: Gesammelte Schrifften und Aufsätze, vol. II, Regensburg 1840, 261-271.

(68) Cf. F. A. Staudenmaier, Das Göttliche Prinzip in der Geschichte und seine Bedeutung für Philosophie und Theologie. Jahrbuch für Theologie und Philosophie 4 (1835), 3-48; P. Hünermann, Trinitarische Anthropologie bei F. A. Staudenmaier, München 1962.

(69) Cf. B. Casper, Der Systemgedanke in der späten Tübinger Schule und in der Neuscholastik, Philosophisches Jahrbuch 72 (1964-65), 161-172. 
forma de experiencia a un nivel superior; la libertad en último término no es algo deducible y derivado, y solo puede experimentarse cuando se revela en la historia.

En las reflexiones de su última época, Staudenmaier se aproxima mucho a la problemática filosófica y teológica actual. Sin embargo, esto significa que gran parte de esta forma de pensar histórica y de la especulación de la escuela más antigua de Tubinga, se nos hace muy extraña, no poseyendo ya una efectividad directa. Nuestra situación se diferencia de la de entonces en un triple sentido: $a$. la teología de Tubinga, aunque en forma de alusiones haya adelantado y anticipado ya muchas cosas, existió antes de que naciera el método histórico-crítico propiamente tal, como lo entendemos actualmente. Entre aquellos teólogos y nosotros media también el nacimiento de las ciencias positivas. El pensar positivo ha ido diferenciando cada vez más nuestros conocimientos en muchos campos de la vida y también los ha ido disociando, de tal manera que actualmente solo sería posible una construcción histórica y filosófica del cristianismo a partir de una idea, a base de armonizar y cercenar cosas de una forma irresponsable. $b$. actualmente el pensamiento filosófico propiamente tal, considera la historia de una manera más radical que entonces, moviéndose en la dirección en la que habían apuntado el Shelling tardío y Staudenmaier. La filosofía especialmente, siguiendo a M. Heidegger, concibe el ser en el horizonte del tiempo, cuestionando así toda la metafísica occidental desde Platón. Ya no concibe el ser en el horizonte de la idea, de la esencia, sustancia y naturaleza, sino en el horizonte del tiempo y de la historia, convirtiéndose así el tiempo en el horizonte supremo de toda la historia (70). Esto significa que ya no es el sujeto pensante quien "domina", penetra especulativamente y construye filosóficamente la realidad; esta solo puede experimentarse, esperarse y enfrentarse como acontecimiento. Por consiguiente, el pensar se convierte en un agradecimiento por lo que existe; vuelve a ser un admirarse de que algo exista, abriéndose de nuevo el campo para lo inesperado, indeducible y para el misterio. Todavía está por ver hasta qué punto con esto no se abren nuevas posibilidades para una experiencia de lo santo y aún de Dios (71). c . dentro de la teología se da una tendencia muy fuerte en correspondencia con esta línea filosófica. La teología moderna ha redescubierto la relevancia y el papel central de la escatología, que se ha convertido en su eje central (p. ejemplo J. B. Metz, K. Rahner, H. U. von Balthasar, W. Pannenberg, J. Noemi). Cada vez se ve más que la escatología no puede ser sino un tratado parcial al final de la dogmática, sino que debe impregnar todo el pensar teológico (72). Estas ideas llevaron en A. Schweitzer y K. Barth, en forma diversa en cada uno, a terminar con una teología determinada por el idealismo, haciendo que nuestra relación actual con la teología tubinguense del último siglo no pueda ser una relación directa. El mensaje de la venida del reino de Dios debe convertirse, actualmente, en un sentido totalmente distinto del de entonces, en la idea central de la teología. Y eso exige un pensar teológico que ya no se mueve en el horizonte de la naturaleza y de las idas eternas, sino en el ámbito de la historia y de la libertad (73).

(70) Cf. O. Pöggeler, El camino del pensar de Martín Heidegger, Madrid ${ }^{2} 1993$, sobre todo 55ss.

(71) N. Corona, Lectura de Heidegger. La cuestión de Dios, Buenos Aires 2002.

(72) Cf. J. Noemi, Esperanza en busca de Inteligencia, 101ss.

(73) Cf. ibíd., especialmente 37 ss. 85 ss. 114 ss. 
Sin embargo, aun en aquellos campos en que existe la mayor diferencia entre el mundo de entonces y el actual, se ve también una estrecha comunidad de problemas. El carácter histórico de toda la realidad, concebido de una manera tan universal y no solo particular, no limitado por consiguiente a un ámbito determinado, no puede ya "dominarse" desde fuera. Ya no cabe el evadirse a un ámbito absolutamente no histórico ni a un ámbito suprahistórico. Lo único posible es intentar probar que la historia no significa puro relativismo, sino que, en cuanto tal, incluye la tradición, la institución y la libertad como algo absoluto e intangible, probando así la validez permanente de lo espiritual; todo eso son constitutivos permanentes y esenciales de Ia misma historia, sin los cuales la historia dejaría de ser historia. Por tanto el pensar histórico implica una "racionabilidad" inmanente, que sin duda nunca puede encerrase en un sistema, pero que sí puede mostrarse hasta en cierto grado.

Estas reflexiones pueden servir para hacer justicia a los planteamientos metodológicos de la teología de Tubinga, especialmente en su forma tardía más desarrollada, tal como se manifiesta en Kuhn y Staudenmaier; y además también para tomar esos planteamientos como base para nuevas posibilidades hermenéuticas de comprensión. También la hermenéutica actual intenta superar la escisión entre método histórico y sistemático, como lo ha intentado Gadamer (74), y reconoce que solo es posible una forma de comprensión histórica si precede un juicio previo y un horizonte racional "sistemático", es decir, envolvente, que naturalmente siempre habrá que estar contrastando con la experiencia; esta confrontación con la experiencia podrá llevar a un desplazamiento, ampliación o síntesis de ese horizonte; pero el conocimiento histórico y el sistemático están fundamentalmente unidos, de tal manera que parece posible trasladar una futura metafísica a una metahistoria.

Las reflexiones precedentes podrían ayudar a una renovación de la metodología teológica. La teología actual se caracteriza por una tensión considerable entre historia, especialmente de la exégesis, y la dogmática; esta a su vez encierra en sí misma esa tensión en la duplicidad del método positivo y especulativo, de la teología esencialista y la existencialista. Esta disociación solo puede superarse por una constante y renovada consideración sobre el carácter esencial y ampliamente histórico del pensar teológico, que encierra en su misma entraña, y no como algo accesorio, la sistemática. La teología entonces debería desarrollarse fundamentalmente presentando las implicaciones de la palabra, dada históricamente, y de la cristología, como un desarrollo de la lógica inmanente de la fe.

En este contexto cobra nueva significación la correspondencia y coordinación que Drey establece entre el hecho, históricamente único, y su autoexplicación en la historia del efecto de ese hecho, o para decirlo en el lenguaje de la teología de entonces, su incardinación en el conjunto orgánico del sistema (entendido históricamente) (75). En el paso histórico del Antiguo al Nuevo Testamento, de la Escritura a la interpretación que de ella hace la Iglesia primitiva, del kerigma al dogma, del

(74) Cf. Verdad y método, vol. 1, Salamanca ${ }^{5}$ 1993; ver igualmente P. Hünermann Das II Vatikanum als Ereignis, 107-126.

(75) Cf. P. Hünermann, Johann Sebastian von Drey und seine Schüler. Stellung und Profil der Tübinger Schule in der katholischen theologie der ersten Hälfte des 19. Jahrhunderts, en: M. Kessler/ O. Fuchs (eds.), Theologie als Instanz der Moderne. Beiträge und Studien zu Johann Sebastian Drey und zur Katholischen Tübinger Schule, Tübingen 2005, 173-189. 
modo de pensamiento específico antiguo y medieval al pensamiento específicamente moderno, de la teología oriental a la occidental, en todo esto se da algo así como una autoexégesis inmanente, una autodesmitologización y autoconcreción de la fe primitiva original, que debe rastrear la teología para llegar a una comprensión íntima y profunda de la fe. Ahora bien, para hacer esto, como ya lo expresó J. E. Kuhn, no pueden darse criterios absolutamente exactos. Es mucho más necesario un tacto espiritual y cristiano, un fino instinto teológico, los "ojos de la fe" (P. Rousselot), para percibir en esas múltiples tradiciones cristianas la tradición única de Cristo. Y esto no es posible sin un horizonte de comprensión previo, sin una idea directriz, que ciertamente es a su vez resultado de una experiencia histórica anterior y que remite a una experiencia histórica futura que la confirme, corrija, prolongue e integre (76).

Luego de haber reseñado las reflexiones de Chenu y la "Escuela de Tubinga" sobre el redescubrimiento de la historia y la historicidad como temáticas irrenunciables para la teología y la autocomprensión del cristianismo y de haber señalado algunos autores que han visto los vasos comunicantes entre estos planteos y el Vaticano II, veremos de qué manera este concilio asume muchos de estos desafíos precedentes.

\subsection{La historia como tema capital del Vaticano II: hacia un repensar las relaciones entre Evangelio e historia}

Mientras que en el pasado se tenía, por lo general, la conciencia de que la historia vivida por los hombres era en última instancia indiferente para la comprensión del Evangelio (hablo de "conciencia", ya que "en realidad" nunca ha sido así), la gran cuestión del Concilio Vaticano II, en cambio, se situaba precisamente ahí, aun cuando las palabras empleadas (carácter pastoral, aggiornamento, signos de los tiempos) no fueron comprendidas enseguida de forma lúcida por todos. Este dato puede quedar ilustrado por numerosos ejemplos. Baste citar uno aquí, el de la discusión que se produjo durante la primera fase del concilio sobre el primer documento doctrinal, que acabaría convirtiéndose en la Constitución Dei Verbum, pero que entonces se llamaba De fontibus revelationis (77). Más que sobre los contenidos precisos de la doctrina de la revelación, entonces se discutió sobre el "carácter pastoral" de la doctrina. Por un lado estaban los que repetían la vieja distinción entre una doctrina que debía ser clara y concisa, y que respetara, como decía el cardenal Ottaviani, la "praxis de los siglos". Por otro, en cambio, quienes, apoyándose en la postura de Juan XXIII tal como había aparecido con la máxima claridad y autoridad en la alocución de apertura Gaudet mater ecclesia (78), pensaban que dicha doctrina se debía formular teniendo presentes las exigencias del hombre contemporáneo. Como lo ha señalado G. Alberigo en relación al estilo predominante

(76) Cf. nuestro análisis al respecto en, Algunas reflexiones sobre el significado del dogma como verdad escatológica sobre el misterio de Dios. La Revista Católica 1.134 (2002), 106-112.

(77) Cf. J. Schmitz, La revelación, Barcelona 1990, sobre todo 80ss.

(78) Cf. Discurso de Juan XXIII en la Inauguración del Concilio: Gaudet Mater Ecclesia (11.10.1962, AAS 54 (1962), 786-796. 
preconciliar, la Iglesia debía abandonar un modo habituado desde siglos al inmovilismo repetitivo e inducido además a considerar esta situación como sinónimo de fidelidad y garantía de gracia divina, lo que implica, a juicio de Chenu, la superación del "tridentinismo" (79).

Para Juan XXIII, la interpretación del Evangelio era inseparable de la referencia a la historia. Para él, conseguir penetrar más profundamente en lo doctrinal requería necesariamente dar cada vez una formulación nueva a la sustancia del Evangelio según las exigencias de los tiempos. Tal formulación nueva es una exigencia de la "continuidad" y no una ruptura. Se trata de comprender que la innovación forma parte de la condición misma de la doctrina cristiana (si no se quiere entender la expresión "depósito de fe" como algo cosificado, una especie de "sustancia" perenne), que respeta su equilibrio interno de contenido que se formula en el tiempo permaneciendo idéntico a sí mismo. La formulación del revestimiento no aparece entonces como algo caduco, sino como imperativo histórico continuamente renovado, como aquello que debe tener en cuenta un magisterio de carácter predominantemente pastoral. Así quedaba introducida la connotación pastoral en el interior mismo de la dimensión doctrinal del cristianismo, como exigencia intrínseca a la doctrina para que su contenido se haga presente en el tiempo: pastoral como hermenéutica histórica de la verdad cristiana (80). Esto último implica, a juicio de G. Alberigo, que la singularidad pastoral del Vaticano II, no permite utilizar la hermenéutica para interpretar los concilios precedentes sino solo de manera análoga (81). O, como bien lo subraya H.-J. Sander, lo pastoral se constituye en la "gramática" del concilio, se constituye en último término, señala este autor, en el lugar donde se lee la voluntad de Dios en los signos de los tiempos (82). O, como lo afirma en un sugerente artículo reciente el mismo autor: "lo que pastoral significa, es la búsqueda de esos signos [de los tiempos] en un doble sentido. Es el camino en el presente, al cual le es dado un nombre en el que su realidad de hecho se abre, y es un camino en el presente, camino que allí lleva la presencia de Dios al lenguaje. Pastoral no es solamente la temporalización de la propia cuestión de Dios, su presentación en la realidad del mundo de hoy, tal como este se da en lo personal, social y religioso. Pastoral es más bien el proceso en el cual se desarrolla un lenguaje para los signos de este tiempo. Pastoral es un proceso semiótico, un proceso que otorga significancia a lo que hoy hay de situaciones humanas o inhumanas, y que abre significancia a lo que el Evangelio allí significa. Desde allí existe la pastoral y

(79) Cf. Cristianísimo e storia nel Vaticano II, Cristianisimo nella storia 3 (1984), 557-592.

(80) Cf. G. Ruggieri, Appunti per una teologia; cf. las lúcidas reflexiones al respecto de P. Hünermann, Zu den Kategorien "Konzil" und "Konzilsentscheidung”. Vorüberlegungen zur Interpretation des II. Vatikanums, en: id., Christlicher Glaube im Horizont globaler Modernizierung 67-82, en donde se habla de la abstracta e inconducente reflexión que no logra mediar entre lo pastoral y lo dogmático como fruto de la síntesis del Concilio Vaticano II.

(81) Critères, 262-263. cf. H. Sauer, Erfahrung und Glaube. Die Begründung des pastoralen Prinzips durch die Offenbarungskonstitution des II. Vatikanischen Konzils, Frankfurt 1993; H.-J. Sander, Die Pastorale Grammatik der Lehre-ein Wille zur Macht von Gottes Heil im Zeichen der Zeit, en: G. Wassilowsky (ed.), Zweites Vatikanum, 185-206.

(82) A propósito del carácter pastoral del Concilio, cf. J. Noemi, El mundo, 228-264; ver también las reflexiones de Balthasar en El Concilio del Espíritu Santo, en íd., Puntos centrales de la fe, Madrid 1985, 85ss. 
a partir de esta doble significancia nace una teología constituida pastoralmente; ella es un proceso semiótico ad extra y ad intra. Es inevitablemente plural, porque nunca existe solamente un signo de los tiempos. Y es inevitablemente universal, porque en estos signos de los tiempos Cristo, el signo del tiempo para todo tiempo, se puede descubrir y mencionar" (83).

Con respecto a lo dicho en el párrafo anterior, K. Lehmann ha subrayado con vehemencia que, más allá de las legítimas diferencias, muchas malinterpretaciones y falsos caminos en la recepción del concilio se han originado a partir de un dualismo "fatal" entre una visión exclusivamente "pastoral" de la realidad y las afirmaciones dogmáticas (84).

La antigua idea de la reforma de la Iglesia, comparada con el aggiornamento pastoral del papa Roncalli, mostraba otro equilibrio respecto a la historia. En ella se enunciaba la exigencia de que en la Iglesia, como consecuencia de las deformaciones producidas respecto a su forma primitiva, como consecuencia de los abusos producidos tanto in capite como in membris, era preciso restaurar la forma auténtica. Esta idea no era negada por la del aggiornamento, pero quedaba ya inmersa en un contexto más vital, que Juan XXIII expresaba con las ideas del rejuvenecimiento de la Iglesia, del jardín que se debía cuidar y no del museo que se había de conservar, etc. G. Alberigo ha subrayado que el aggiornamento es la meta del concilio: "La importancia hermenéutica del aggiornamento, más allá de la dificultad de una determinación conceptual rigurosa del término, está estrechamente ligada al carácter pastoral del concilio. Aggiornamento ha sido comprendido como 'reforma', cuando quiere indicar más bien una disponibilidad y una aptitud al cambio, un compromiso global en vistas de una inculturación renovada de la revelación en las nuevas culturas" (85).

Ahora, pues, se trataba de redescubrir hasta el fondo el sentido de la historia vivida e interpretada por los hombres como lugar teológico. Nótese bien: se quiere hablar de la historia realmente vivida, no de la simple historia narrada, al modo en que la concebía el tratado tradicional de los loci theologici (86), que veía la historia como un conjunto de fuentes y documentos de los que extraer argumentos sustentadores de la verdad afirmada en la Iglesia. Solo si se tiene presente la historia vivida e interpretada por los hombres resulta fundamental la categoría de los "signos de los tiempos". Pero esto implica otra tarea que aún tenemos íntegra ante nosotros, y es la superación de la hegemonía de la teología, entendida como aislamiento de la dimensión doctrinal de la fe y su conceptualización abstracta, y también del "juridicismo", en cuanto anquilosamiento del dinamismo de la experiencia cristiana en fórmulas jurídicas.

(83) Die Zeichen der Zeit erkennen und Gott benennen. Der semiotische Charakter von Theologie, Theologische Quartalschrift 182 (2002), 35.

(84) Cf. Hermeneutik, 71-89.

(85) Critères, 271-272.

(86) Para una relectura de la teología actual de Cano, cf. B. Corner, Melchior Cano. De locis theologicis. Ein Beiträg zur theologischen Erkenntnislehre, Graz 1992; P. Hünermann, Dogmatische Prinzipienlehre. Glaube-Überlieferung-Theologie als Sprach- und Wahrheitsgeschehen, Münster 2003 . 


\section{EL CONCILIO COMO “CORTE” E “INICIO” (87)}

K. Rahner (88), en una lectura profunda del significado histórico-teológico del último concilio, sostenía la tesis de que, de algún modo, el corte conciliar se podía comparar solo con el de los comienzos de la Iglesia primitiva, cuando los discípulos, con la fuerza del Espíritu del Resucitado, tomaron iniciativas que no representaban la simple continuidad con la enseñanza de Jesús: "Vivimos hoy por vez primera en la época de un corte tal, como solo se verificó en el paso del judeocristianismo al pagano-cristianismo" (89). Como consecuencia de esta interpretación, el significado del Vaticano II consiste en el hecho de que "en él, aun cuando solo de manera inicial y poco clara, la Iglesia proclamó el paso de la Iglesia occidental a una Iglesia universal, en un sentido que, hasta ahora, solo se había verificado, por primera y única vez, cuando la Iglesia de los judíos se convirtió en Iglesia de los paganos" (90). De otra manera, Metz ha formulado esta constatación de Rahner de la siguiente manera: "El cristianismo, que, después de una corta época de fundación en el judeocristianismo, se debía a un espacio cultural relativamente unitario a lo largo de alrededor de dos mil años, a saber, el espacio cultural occidental-europeo, hoy día se abre a un cristianismo mundial que debe enraizarse culturalmente de modos diversos. Se sitúa en el camino de un cristianismo culturalmente monocéntrico europeo hacia un cristianismo universal culturalmente policéntrico. ¿Cómo entiende y asume la teología esta diversificación étnico-cultural?" (91). A partir de esta hipótesis interpretativa, que en nuestros días ha sido reflexionada a fondo por Hünermann (92), se plantean una serie de cuestiones abiertas, la primera de las cuales dice así: "si la Iglesia posee aun en la época postapostólica, y en qué medida, el poder y la energía creadora que tuvo y pretendió tener en la época de su primer devenir para tomar decisiones fundamentales irreversibles, o aparentemente tales, que por primera vez la constituyeron en su naturaleza concreta, más allá de cuanto le fue asignado con realidad inmediata por Jesús Resucitado" (93). Y queda abierta otra cuestión fundamental: si la

(87) Aquí no entramos en la discusión si es preferible hablar de un segundo o tercer "corte", para ello cf. lo expuesto en la nota siguiente.

(88) Theologische Grundinterpretation des II. Vatikanischen Konzils, en: íd., Schriften zur Theologie, vol. XIV, Einsiedeln 1980, 287-302. Junto con esta importante esquematización histórico-teológica del Vaticano II se debe recordar otra, según la cual en la historia de la Iglesia no solo existe el corte de la Iglesia primitiva, sino también el de la era constantiniana, por lo cual el Vaticano II vendría a ser el tercer corte (cf. M.-D. Chenu, La fin de l'ére constantinienne, en: Un concile pour notre temps, Paris 1961, 59-87). Entre la amplia literatura que testimonia el influjo de Rahner en el Concilio, cf. G. Wassilowsky, Universales Heilssakramet Kirche. Karl Rahners Beitrag zur Ekklesiologie des II. Vatikanums, Innsbruck 2001; íd., Karl Rahners, sobre todo 48ss; H.-J. Sander, Die pastorale Grammatik, sobre todo 192ss; AAVV, Karl Rahner. La actualidad de su pensamiento (incluye la conferencia El Concilio, nuevo comienzo, de Rahner), Barcelona 2004; C. Schickendantz, Cambio estructural en la Iglesia; S. Madrigal, Glosas marginales de K. Rahner sobre el concilio Vaticano II, Estudios Eclesiásticos 89 (2005), 339-389.

(89) Theologische Grundinterpretation, 297.

(90) Ibíd.

(91) Theologie versus Polymythie oder Kleine Apologie des biblischen Monotheismus, en: Einheit und Vielheit X/V. Deutscher Kongress für Philosophie, Hamburgo 1987, 185.

(92) Cf. P. Hünermann, Konkretion und Geist, 216-227.

(93) K. Rahner, Theologische Grundinterpretation, 299. 
Iglesia, ante este nuevo corte, puede percibir, y en qué medida, posibilidades de las cuales nunca antes había hecho uso porque habría sido ilegítimo.

Como se puede ver por lo que acabamos de decir, una vez aceptada la hipótesis interpretativa de Rahner, la consecuencia no sería la anulación de la tradición eclesial. Lo mismo que los discípulos, ante el "tercer ausente", en el sentido de M. de Certeau (94), es decir, frente a un sujeto cultural nuevo (nuevo respecto al sujeto tradicional judío y respecto al nuevo sujeto cristiano que eran ellos mismos), debieron repensar creativamente el Antiguo Testamento y la cultura judía a partir de su fe en Jesucristo, otro tanto deben hacer hoy las Iglesias. Nos encontramos ante un nuevo inicio (95). Surge de forma inédita un pluralismo de culturas y de pueblos que, con la conciencia histórica que hoy tenemos de dicho pluralismo y de su dignidad, no es comparable con el de las épocas pasadas (96). Pero el "inicio" no es un inicio absoluto. Esto sería impensable para los cristianos. Nadie puede construir sobre un fundamento distinto del que "ha sido puesto". Se trata más bien de la

(94) Para Certeau (cf. por ejemplo L'Etranger ou l'union dans la différence, Paris 1969; La faiblesse de croire, Paris 1987; La culture au pluriel, Paris 1974; M. de Certeau/François Roustang, La Solitude - une vérité oubliée de la communication, Paris 1967), un criterio esencial para la caracterización de lo cristiano, la "discreción de espíritus" de las formas de vivir en la variedad de culturas, lo constituye la praxis del real "reconocimiento del otro" que permite vivir y dar vida en la comunión. A esto pertenece la apertura radical hacia el foráneo, la disposición de aprender del otro y del desconocido, de partir hacia lo nuevo. A esto pertenece promover la vida en las formas de vida y praxis, hacer posible una vida en verdad y plenitud para muchos, promover las culturas de tal manera que crezcan en su propia identidad y que en ellas puedan identificarse formas del amor. Y también pertenece a esto no olvidar desgracias del pasado, sino ubicarlas en el ámbito de posibilidades de Dios para que pueda -esta es la experiencia del espíritu- volver a abrirse un futuro. Tal praxis que se vale nuevamente del lenguaje del amor, nace del confiar y de la esperanza de la mañana aún remota, pero cuya expectativa permite soportar la oscuridad y el dolor. Así lo ejemplifican los monjes que pasan la noche rezando y esperando la mañana con todas las fibras de su alma, una imagen que emplea Michel de Certeau. Esta expectativa y esperanza del Dios más fuerte es el motivo más profundo del "consuelo" que identifica las diversas formas de vida y praxis como cristianas, como formas del amor. Desde un punto de vista eclesiológico, estas intuiciones de Certeau se pueden prolongar para interpretar la fe cristiana así vivida como experiencia de fragilidad, "hacerse huésped de otro que inquieta y hace vivir". Esta experiencia no es nueva, pues los místicos y espirituales son un signo siempre vivo de aquello. Hoy esa experiencia se hace colectiva, como si el cuerpo entero de las iglesias debieran vivir lo que el cristianismo ha anunciado siempre, que Jesucristo ha muerto. Esta muerte, señala Certeau, "no es solo el objeto del mensaje que se refiere a Jesús, sino la experiencia de los mensajeros. Las iglesias, y no solo el Jesús de que hablan, parecen llamadas a esta muerte por la ley de la historia. Se trata de aceptar ser débil, de abandonar las máscaras ridículas e hipócritas de un poder eclesial que ya no existe". El problema no consiste según este jesuita francés en saber si será posible restaurar la empresa Iglesia, según las reglas de la restauración y saneamiento de todas las empresas. La única cuestión que vale es: “¿habrá cristianos dispuestos a buscar esas aperturas orantes, errantes, admiradoras? Si hay hombres todavía dispuestos a entrar en esa experiencia de fe, que reconozcan en ella lo que necesitan, les tocará poner de acuerdo su Iglesia con su fe, buscar en ella no ya modelos sociales, políticos o éticos, sino experiencias creyentes y sus correspondientes comunicaciones; sin ello no habría más comunidades ni itinerancias cristianas" (cf. La faiblesse, 304-305); cf. L. Mantuano, Lo straniero o l'unione nella differenza, Sulla teologia de Michel de Certeau, Asprensas 42 (1995), 21-36; M. Eckholt, Nicht ohne Dich; el número 136 (2004) de la Revue de théologie et de philosophie está dedicado a los aportes de Certeau, especialmente interesante el artículo de P. Gisel, Lire Michel de Certeau en théologien, $399-416$

(95) Cf. para los término nuevo y novedad aquí aplicados, G. Alberigo, Critères, 270ss.

(96) Cf. M. Eckholt, Hermeneutik und Theologie bei Paul Ricoeur. Denkanstöße für eine Theologie im Plularismus der Kulturen, München 2002. 
interpretación creativa que redescubre posibilidades de la tradición de las cuales no se había hecho uso nunca, porque la historia pasada no las vislumbraba o las consideraba directamente vedadas. Como bien anota A. Dulles, la presentación del Vaticano II de la tradición como proceso dinámico ha sido su logro teológico más importante: "Como resultado del concilio, los católicos pueden admitir ahora de buen grado que algunos de sus dogmas pueden haber sido desconocidos y hasta ininteligibles para los cristianos de los primeros siglos. Un dogma como el de la Inmaculada Concepción puede emerger en el curso de los siglos con las más débiles justificaciones documentales apostólicas y, no obstante, ser 'tradicional' en cuanto está inspirado por el Espíritu Santo, que sigue actuando permanentemente en la Iglesia", y continúa más adelante en una alusión al Espíritu que nos remite a lo dicho por nosotros en seguida sobre la epíclesis, "por último, al conectar directamente la tradición con el Espíritu Santo como sujeto trascendente y al desacoplarla de las tradiciones (en plural), el concilio ha legitimado el programa de renovación y de reforma que estaba en el núcleo del Vaticano II. Ha permitido a los católicos ser críticos frente a ciertos aspectos de su propia herencia y deshacerse de todo lo que pudiese verse como algo culturalmente condicionado. Muchos católicos se han sentido autorizados por el concilio para transformarse en ciudadanos del mundo moderno con todas las de la ley, para abrirse a las riquezas espirituales de las culturas noeuropeas y para comprometerse en el diálogo" (97).

Este fue, por lo demás, el verdadero significado del gran debate sobre la tradición que se mantuvo en el Vaticano II. Fue un debate que no tuvo un resultado satisfactorio. Siguió estando demasiado cautivo del clima postridentino, ya que se vio en tensión entre la recuperación de la tradición "viva", por una parte, y, por otra, la contestación que por diversos motivos se hacía de esta concepción vitalista de la tradición por parte de los conservadores a ultranza, pero también por aquellos que no querían anular la función normativa de las Escrituras respecto a los desarrollos sucesivos de la tradición eclesial (98).

Sin duda el diálogo con la tradición oriental (v. gr. Iglesia ortodoxa) durante y después del concilio ha servido para tomar conciencia que el debate recién señalado era y es interno a la tradición latina, cautiva a veces de la oposición interpretativa jurídica entre Escritura y Tradición. El diálogo recién mencionado nos ha hecho a los católicos estar más atentos a la propuesta ortodoxa-oriental de una concepción de la tradición como epíclesis de la historia de la salvación, es decir, teofanía del Espíritu Santo, sin la cual la historia del mundo es incomprensible, y la Sagrada Escritura se queda en letra muerta (99). En el curso de las mismas sesiones el cardenal Meyer declaró: "Nos complace que por fin tengamos una concepción viva,

(97) El oficio de la teología, 117ss; cf. íd., The Role of the Tradition in Catholic Christianity, Emmanuel 96 (1990), 4-29; R. P. Imbelli, Vatican II- Twenty Years Later, Commonweal 109 (1982), 78ss.

(98) Cf. A. Buckenmaier, "Schrift und Tradition" seit dem Vatikanum II. Vorgeschichte und Rezeption, Padderborn 1996; D. Wiederkehr (ed.), Wie geschiet Tradition. Überlieferung im Lebensprozess der Kirche, Friburgo et al. 1991.

(99) Cf. M. Edelby, Nueva conciencia del fundamento trinitario de la Iglesia, Concilium 166 (1981), 343; cf. las sugerentes reflexiones de P. M. Pagano, Espíritu Santo-Epíclesis-Iglesia. Aportes a la eclesiología eucarística, Salamanca 1998, sobre todo 39ss; cf. también, K. Lehmann, Hermeneutik, 79ss. 
dinámica, global de la Tradición, que no sea restringida a unas formulaciones doctrinales y que se extienda a la liturgia y a la praxis de la Iglesia. Aprobamos que se diga que no se desarrolla únicamente por medio de las definiciones del magisterio, sino también mediante la contemplación de los fieles y en virtud de la experiencia íntima de las cosas espirituales" (100).

El que la cristología necesariamente tenga que ser siempre más elocuente que la pneumatología es una afirmación más que discutible. Con ella podría justificarse indebidamente un déficit objetivo del Occidente cristiano que ha sido denunciado con vehemencia, pero no sin razón, por la Iglesia de Oriente y al que la modernidad nos confronta como una tarea urgente. Así por ejemplo, el teólogo ortodoxo V. Lossky denuncia que en Occidente el Espíritu se esfuma y se hipertrofia la economía del Verbo. La vida cristiana solo puede ser concebida como imitación de Cristo y no más divinización operada por el Espíritu. A su juicio esto trae como consecuencia que el carisma sucumbe ante la institución, la libertad ante la autoridad, el profetismo ante el juridismo, la mística ante la escolástica, el laicado ante el clero. El Espíritu se deforma como burda garantía de lo establecido (101). El desarrollo de una "cristología pneumática" (con esta expresión nos referimos al intento pionero en la teología actual de P. Schoonenberg que intenta elaborar una cristología sistemática del Espíritu (102), y a las exigencias planteadas por W. Kasper de una cristología que tiene que ser también "pneumato-lógica, en cuanto que solo en el Espíritu, que se nos ha prometido y se nos ha dado, puede resplandecer la unidad de Jesucristo con Dios y su comunión con cada uno de nosotros" (103)) no solo es un imperativo ecuménico con respecto a las iglesias ortodoxas que no es legítimo postergar por más tiempo sino que "descubrir" al Espíritu implica un requisito inalienable para que la Iglesia cumpla cabalmente su rol de evangelizadora, todavía mucho más si es preciso hacer esto en la modernidad y no al margen de la misma. M. Bordoni delimita acertadamente este desafío cuando lo describe como "comprender la urgencia, para la situación actual del hombre religioso, de la profundización teológica en la relación entre cristología y pneumatología. En realidad la cristología, en cuanto discurso reflexivo de la fe sobre el misterio de Jesús como Cristo y Señor, no puede desarrollarse sino en el lugar del Espíritu Santo, a pesar de que este lugar no haya sido puesto siempre en evidencia como habría merecido. La cuestión cristológica que ha tenido siempre como su principal motivo crítico el problema de Dios, se pone hoy día más específicamente como cuestión pneumatológica" (104). De esta forma, la teología actual debería acometer la tarea de pensar al Espíritu como la persona trinitaria vicinior nobis, más próxima a nosotros, como nos enseña la teología tradicionalmente, es decir, el Espíritu concentra en sí mismo la actualización de la dimensión inmanente que le corresponde al Dios de Jesucristo. La plenitud del ser

(100) Nueva conciencia del fundamento trinitario de la Iglesia, Concilium 166 (1981), 343.

(101) Cf. V. Lossky, Teología mística de la Iglesia de Oriente, Barcelona 1982.

(102) Cf. El Espíritu, la Palabra y el Hijo. Una Cristología del Espíritu, Salamanca 1998; ver además para el ensayo de este autor, B. Blankenburg, Gottes Geist in der Theologie Schoonenbergs, Mainz 2000; M. Preß, Jesus und der Geist. Grundlagen einer Geist-Christologie, NeukirchenVluyn 2001.

(103) Prólogo a la undécima edición de Jesús el Cristo, Salamanca 2002, 34.

(104) La cristologia nell'orizonte dello Spirito, Brescia 1995, 12. 
un Dios con nosotros del Dios bíblico se cumple en el Espíritu, ya presente en la creación del mundo. El Espíritu representa la garantía de un Dios que compromete realmente su trascendencia con la inmanencia de lo creado. No solo al Espíritu debemos el que la historia del Padre y del Hijo se convierta en la historia del que nos asume y salva, el que Dios entregue al Hijo al mundo, sino que el Espíritu se identifica con el don que Dios hace de sí mismo precisamente como Espíritu. Así el Trascendente se hace inmanente sin perder su trascendencia sino como transformador y recreador de la inmanencia.

Este protagonismo del Espíritu como agente de Dios que se hace inmanente en la creación sin perder su trascendencia lo grafica muy bien la doctrina tradicional acerca de la gracia creada y la gracia increada (105). Todo el discurso sobre la gracia creada de Tomás de Aquino, que le permitirá a Trento superar el extrinsicismo del planteo protestante acerca de la justificación, es dependiente de su planteo sobre la gracia increada como el don del Espíritu. El realismo católico sobre la gracia en cuanto creada es dependiente de la fundamentalidad con que el Espíritu es concebido como Dios hecho don, como gracia increada. Ahora bien, el discurso católico antiprotestante sobre la gracia creada puede malentenderse como postulado mágico y supersticioso en la medida que se independiza de la pneumatología, en la medida que no lo refiere al Espíritu como el don increado que recrea. En este sentido me parece plenamente válido lo que nota K. Lehmann, es decir, que "una renovación es solo posible cuando la pneumatología sea algo así como una permanente filigrana o un activo soporte estructural de la doctrina de la gracia" (106). La emergencia que adquiere un desarrollo de la pneumatología en el contexto de la modernidad está en correlación y dependencia del complejo desafío que representa desentrañar la esperanza de la razón moderna, como lo ha intentado recientemente J. Noemi en su ensayo Esperanza en busca de inteligencia. Baste aquí anotar que el inmanentismo de la razón moderna no es equivalente a un secularismo ramplón y arreligioso, sino que comporta el reclamo de una inmanencia sin trascendencia, de un mundo sin Dios, ante la oferta de una trascendencia sin inmanencia, de un Dios sin mundo. Como la teología nunca ha sido un lujo para la Iglesia sino requisito insustituible de su sacramentalidad, el desarrollo de la pneumatología y más específicamente el desentrañar la esperanza del mundo moderno se perfilan como tareas irrecusables para la evangelización en el mundo de hoy. La teología debe entonces contribuir al descubrimiento del Espíritu como Aquel que construye el reino de Dios en el curso de la historia para, consecuentemente, redescubrir la virtud teologal de la esperanza como exigencia de desentrañar la esperanza del mundo moderno.

Al terminar esta breve reflexión sobre las relaciones entre pneumatología y cristología valgan los testimonios de dos teólogos que han llamado la atención sobre los necesarios vínculos entre cristología y pneumatología. El primero es de quien probablemente más ha ayudado a tomar conciencia de los déficit de un divorcio

(105) Cf. J. Noemi, Antropología Teológica II. Pensar el don de Dios (Schemata lectionum ad usum auditorium), Santiago 1983, 84ss.

(106) Heiliger Geist, Befreiung zur Mehschsein. Teilhabe am göttlichen Leben.Tendenzen gegenwärtiger Gnadenlehre, en: W. Kasper et al. (ed.), Gegenwart des Geistes, Freiburg 1979, 202. cf. en la misma línea los sugerentes planteos de A. Meis en su Antropología Teológica, Santiago 1998. 
entre ambas temáticas teológicas como lo es W. Kasper: "Estas reflexiones algo abstractas se tornan concretas, si el problema de la unicidad y universalidad del cristianismo, nos lo planteamos teológicamente. Según el Antiguo y el Nuevo Testamento, la conciliación entre ambas se da por medio del Espíritu de Dios. El Espíritu, según la Biblia, actúa donde quiera hay o surge vida... Sobre todo actúa allí donde la creación se afana y aspira más allá de sí misma hacia la plenitud escatológica. Solo en la participación de la fuerza y poder creadores de toda vida, puede el hombre llenar la autotranscendencia de su existencia, su nostalgia por el 'completamente-otro' (M. Horkheimer). El Espíritu se apiada... del sufrimiento de la... creación, y la lleva a su meta, al reino de la libertad. El Espíritu es la fuerza creadora e histórica de Dios... que entra en acción allí donde hay hombres que... se empeñan por realizar el futuro de la libertad, la justicia y el amor. Sin embargo, esta acción es continuamente cancelada por el pecado... Únicamente en la absoluta obediencia de Jesús hasta la Cruz, llega el Espíritu hasta el final. Así, Jesús nos es anunciado en el Nuevo Testamento como el portador por antonomasia del Espíritu... En él se ha apiadado Dios definitivamente del afán y la nostalgia de su criatura, y ha puesto el comienzo escatológico de la libertad. Esta perspectiva pneumatológica hace ver mejor la unicidad y universalidad de Jesucristo. Allí donde el hombre... se entrega al futuro de Dios, allí anticipa algo de la realidad que apareció en toda su plenitud en Jesucristo. Allí donde el hombre se entrega a la aventura de su vida, se esfuerza por la verdad y la justicia, perdona y disculpa posibilitando así un nuevo comienzo, donde uno abandona su vida pasada y comienza de nuevo, donde se producen florecimientos espirituales y religiosos, allí está previamente en acción la gracia de Jesucristo, si se quiere, anónimamente. En la convicción cristiana hay, sin embargo, un solo 'caso', en el que el Espíritu ha encontrado de manera única una aceptación no desfigurada y limpia: en Jesucristo, que en la fuerza del Espíritu fue forma completamente libre y dispuesta para la autocomunicación de Dios. En él el Espíritu ha alcanzado su meta. La función del Espíritu es ahora recordar a Jesucristo y hacerle presente en su novedad. Por consiguiente, el Espíritu romperá continuamente las formas anquilosadas y rígidas del cristianismo, al exhortar a los cristianos a oír la 'profecía exterior' del mundo y a estar atentos a los 'signos de los tiempos', es decir, a la actuación del Espíritu fuera de la Iglesia. Y al contrario, el Espíritu de Jesucristo asume las esperanzas y anhelos de la criatura atormentada, para llevarlas por Jesucristo a su más profunda realización. Así el Espíritu de Cristo hace presente de un modo universal la única obra salvífica y, al mismo tiempo, le confiere su concreta universalidad y catolicidad, al incorporar al cristianismo, crítica y creativamente, todas las riquezas de los pueblos y religiones" (107). El segundo es de Rahner, que si bien no desarrolló lo que se puede llamar una pneumatología sistemática, si estuvo muy atento al equilibrio que debe haber en la dogmática entre cristología y pneumatología a la hora de perfilar la misión de la Iglesia frente nuevos desafíos a la luz del cambio estructural eclesial que supuso el Vaticano II: "El Espíritu de Dios sopla en la Iglesia no únicamente porque empiece a operar en sus más altos funcionarios. Hay una efectividad carismática del Espíritu en nuevos co-

(107) Unicidad y universalidad de Jesucristo, 270-271 (subrayado CC). 
nocimientos, en formas nuevas de la vida cristiana para nuevas decisiones de las que depende el destino del reino de Dios; efectividad del Espíritu, que comienza en la Iglesia allí donde quiere el Espíritu mismo. Este puede dar también a los pobres y pequeños, a las mujeres y niños, a los no empleados, en una palabra, a cada miembro en la Iglesia, y no solo a los jerarcas, un encargo grande o pequeño en el reino de Dios y para la Iglesia. Los carismáticos libres... han de vivir en paz con los portadores del ministerio; estos han de examinar con el carisma del discernimiento de espíritus, han de regular, de disponer, para provecho de la Iglesia entera, el imperio del Espíritu en los carismáticos libres. Pero el ministerio en la Iglesia no puede pensar nunca que todo depende de él... No, no; en la Iglesia hay lo que no es planificable, lo no institucional, lo sorprendente, y por eso auténtica historia de la Iglesia, que no solo es la ejecución de un plan de construcción, sabido siempre de antemano, de la casa de Dios. Existe lo carismático en la Iglesia en cuanto momentos de esa Iglesia, y solo con él es esta lo que según la voluntad de Cristo debe ser y también lo que siempre llegará a ser por medio de su Espíritu" (108).

Valga aquí la pena recordar por último que la expresión "nuevo pentecostés" está en el mismo campo temático (y semántico) de lo que se podría llamar "epiclético", en el que son relacionados formalmente misión de la Iglesia e historia y en el que la renovación de la Iglesia está encaminada a una destinación escatológica, precisamente contraria a un conservatismo nostálgico. Como nos recuerda el papa Roncalli: "Nuestro deber no es solo custodiar ese tesoro precioso [la tradición católica], como si únicamente nos ocupásemos de la antigüedad, sino también dedicarnos con voluntad diligente, sin temores, a la labor que exige nuestro tiempo, prosiguiendo el camino que la Iglesia recorre desde hace veinte siglos" (109). Es un "paso adelante" como el mismo Papa señala, que podría fracasar si por falsa gravedad, inmovilismo o miedo al futuro, se renunciara a la urgencia pneumática de la renovación y al aggiornamento que son exigidos a la Iglesia. G. Alberigo comenta: "Se considera pues legítimo liquidar el Vaticano II como afectado de optimismo fácil, evitando confrontarse con la posición profunda del mismo, indicada en su apertura por Juan XXIII y compartida por la gran mayoría de los Padres, según la cual había llegado el momento de reanudar la lectura escatológica de la historia, superando la miopía del 'profetismo de desventura'. Para ser capaz de un 'nuevo Pentecostés', la Iglesia necesita sacudir de sí muchas incrustaciones seculares que parecen ornamentos, pero que no son más que residuos polvorientos de un pasado que no puede volver. Solo la renovación interna en torno a la sustancia de la fe puede hacer a la Iglesia capaz de vivir con sencilla autenticidad en la historia, protegida solamente por la pobreza del Evangelio" (110).

(108) Zur Theologie des Konzils, 287-289; cf. la amplia y profunda obra de G. Cislaghi, Per une ecclesiologia pneumatologica. Il Concilio Vaticano II e una proposta sistematica, Milán 2004.

(109) Gaudet Mater Ecclesia, n. 14.

(110) La condición cristiana después del Vaticano II, en: G. Alberigo/J.P. Jossua (eds.), La recepción del Vaticano II, Madrid 1987, 43; ver también las lúcidas reflexiones de Von Balthasar en El Concilio, 85-104. Rahner en su contribución "Sobre la teología del concilio" también había llamado la atención sobre este carácter espiritual de la Iglesia en relación a su misión (Zur Theologie des Konzils, en: íd., Schriften zur Theologie, vol. V, Einsiedeln 1962, 278-302 ([hay traducción al español]). 


\section{LOS SIGNOS DE LOS TIEMPOS (111)}

El problema fundamental que se plantea a partir de los puntos anteriores es, pues, redescubrir el nexo entre la historia y el Espíritu de Cristo, de tal manera que Los nuevos interrogantes de la historia permitan comprender de nuevo el Evangelio en el tiempo. Resulta necesaria, por tanto, una teología de los "signos de los tiempos”. Por desgracia, más allá de la inflación de la expresión, que por lo general se usa para indicar los rasgos que caracterizan nuestra época histórica, la teología posconciliar no ha sabido ahondar el significado teológico hermenéutico de esta categoría.

Solo recientemente los trabajos de, entre otros, P. Hünermann, G. Ruggieri y H.-J. Sander han subrayado el carácter eminentemente teológico de esta categoría que integra así sus otros contenidos. Así por ejemplo Hünermann caracteriza a los signos de los tiempos de la siguiente manera: "Bajo 'signo de los tiempos' el Concilio Vaticano II ha señalado acontecimientos históricos o realidades en los cuales el Espíritu de Dios y sus obras resplandecen. El concilio ha exhortado a los cristianos a tomar en serio esos signos y ha reconocer en ellos la presencia y llamado de Dios" (112).

Esta categoría, ya estaba presente antes, sobre todo en la teología y la predicación protestante del siglo XIX y también en la teología Chenu (113) y la divulgación católica de la primera mitad de nuestro siglo. Chenu nos indica que la expresión ocupada por el concilio, y de la que el fue promotor, lejos de ser un obiter dictum, empleada una sola vez, sin referencia escriturística, debe ser "considerada e interpretada como una de las tres o cuatro fórmulas más significativas del concilio" (114). Ello debido a que la idea que ella expresa es "constitutiva del tejido mismo de la doctrina del concilio" (115): la intención de aggiornamento de la Iglesia exigía el discernimiento de los valores terrenos, que percibidos por la Iglesia la harían ponerse al día, la expresión manifiesta densamente la "ley de coherencia entre el mundo en construcción y la Iglesia en evangelización” (116). Recoge las exigencias

(111) Cf. A. Wollbold, art. Zeichen der Zeit, en: W. Kasper (ed.), Lexikon für Theologie und Kirche, vol. 10 Friburgo ${ }^{3} 2001,1403$; id., Nach den Zeichen der Zeit zu forschen und sie im Licht des Evangelium deuten: Nachfragen zur Methode der Pastoraltheologie, en: B. Pittner/A. Wollbold (eds.), Zeiten des Übergangs (FS F.G. Friemel), Leipzig 2000; Ph. Bordeyne, Ambiguïtés de la mémorie et mémorie de l'ambïguité: quelques observations sur le concept de signes des temps, Revue d'ethique et de théologie morale 212 (2000), 51-70; H. Schmidinger (ed.), Zeichen der Zeit: Erkennen und Handelns, Innsbruck 1998; G. Ruggieri, La teologia dei "segni dei tempi": acquisizione e compiti, en: G. Canobbio (ed.), Associazione Teologica Italiana. Teologia e storia, 33-77; P. Hünermann; Zeichen der Zeit, 275-280. Para una panorámica de está temática en la teología latinoamericana cf. F. Parra, Desafío a la credibilidad de la Iglesia en América Latina, Teología y Vida 45 (2004), 258-272; J. L. Segundo, Revelación, fe, signo de los tiempos, en: I. Ellacuría/J. Sobrino (eds.), Mysterium Liberationis. Conceptos fundamentales de la teología de la liberación, vol. 1, Madrid 1990, 443-466.

(112) Zeichen der Zeit, 280, n. 9.

(113) Cf. las pertinentes reflexiones sobre Chenu de E. Silva, Marie-Dominique Chenu: un teólogo de los signos de los tiempos, 115-150; íd., M.-D. Chenu, la significación teológica de los acontecimientos, 269-279; G. Ruggieri, La teologia dei, especialmente 49ss.

(114) Les signes des temps, 97.

(115) Ibíd.

(116) Ibíd. 
de una "historia de salvación" y de la dimensión "profética" de la Iglesia, y "llega a ser una de las categorías fundamentales de la teología actual" (117). En sus estudios sobre esta expresión conciliar, a la que Chenu da el rango de "categoría teológica", procura respetar tanto el aspecto significativo como el aspecto significante de estos signos. Es imprescindible mantener la densidad histórica de esta categoría teológica, al tiempo que se afirma la significación teológica de acontecimientos históricos. Junto con evitar el riesgo de vaciar de su contenido a estos fenómenos históricos, convirtiéndolos en meros símbolos u ocasiones destemporalizadas, se trata de leer el sentido divino de tales acontecimientos, reconociendo en ellos los signos del designio creador y liberador de Dios. De no hacerlo no tendremos la inteligencia de la fe que descubre el misterio en su realización.

Esta categoría hizo su entrada "oficial" en la teología católica el 25 de diciembre de 1961, a través de la bula de convocatoria del Vaticano II, Humanae salutis.

\subsection{Los signos de los tiempos en la intención convocatoria de Juan XXIII (118)}

El papa Roncalli escribía: "siguiendo la recomendación de Jesús cuando nos exhorta a distinguir los 'signos de los tiempos' (Mt 16,4), nos creemos vislumbrar, en medio de tantas tinieblas, no pocos indicios que nos hacen concebir esperanzas de tiempos mejores para la Iglesia y la Humanidad" (119). El concilio, a su vez, retomará esa expresión cuatro veces en sus documentos finales (120), aun cuando el concepto como tal se repite con mayor frecuencia. La expresión contenía un sentido positivo y de esperanza, pero su significado principal no se podía reducir a esto.

El hecho de que un Papa pretendiese ver en la historia concreta de su propio tiempo signos positivos "que hacen concebir esperanzas de tiempos mejores para la Iglesia y la Humanidad" (121) puede parecer hoy banal o indiferente. Sin embargo, en Juan XXIII aquella expresión estaba bien meditada y pretendía corregir una visión (la de los "profetas de desgracias") de algún modo dominante en la tradición de la Iglesia católica, desde la Restauración del siglo XIX, hasta toda la primera mitad de nuestro siglo y que hoy en día ha vuelto a tener cierta vigencia en algunos medios eclesiales. A partir de la Revolución Francesa, el magisterio católico se había anquilosado en una valoración negativa de la historia moderna. Aun cuando dicha valoración hunde sus raíces en la apologética del siglo XVIII, se puede citar como fecha "ideal" de su inicio la encíclica Mirari vos (15 de agosto de 1832) de Gregorio XVI (122), el cual ve la historia contemporánea bajo el signo de una "conjura de los malvados" que no permitía indulgencia ni benignidad alguna por parte de la Iglesia, e imponía más bien "reprimir con la vara" los diversos errores. Este juicio globalmente negativo sobre la historia y sobre la sociedad occidental, sobre todo acerca de las sociedades democráticas, no solo fue retomado en el magis-

(117) Ibíd.

(118) Cf. G. Ruggieri, La teologia dei, especialmente 38ss.

(119) "Immo vero, monitis obsecuti Christus Domini nmos hortantis ut signa ... temporum" (Humanae Salutis, 25-dic-1961, AAS 54 [1962], 5-13, aquí 6).

(120) Gaudium et spes 4, Presbyterorum ordinis 9; Apostolicam actuositatem 14; Unitatis redintegratio 4.

(121) Humanae Salutis, 6.

(122) Cf. DH 2730-2732. 
terio de Pío IX (baste citar el Silabo (123)), sino que quedó solemnemente codificado, por decirlo así, en el proemio que abre la Constitución Dogmática del Vaticano I sobre la fe católica Dei Filius (124): la historia moderna, tras el concilio tridentino, es descrita como la progresiva corrupción del hombre, provocada por la negación protestante del principio de autoridad. En un estudio magnífico de H. J. Pottmeyer sobre este proemio se subraya la dificultad para hacerse cargo de pensar la historia antes que condenarla (125). Sobre la vigencia de esta sospecha frente al tiempo y a la historia nos queremos referir en el siguiente párrafo por considerar que, aunque con otro lenguaje, por cierto más "moderno", persiste aún una visión no del todo positiva de ambos elementos constitutivos de la visión del hombre actual.

Para este análisis nos remitimos especialmente a las reflexiones que ha ofrecido últimamente J. Noemi (126). Si se consideran los antecedentes que condicionan una fuga temporis en la historia del pensamiento, se pueden señalar, entre otros, tres tipos de la misma que es posible distinguir en la actualidad. Un primer tipo de evasión del tiempo es el que podría tipificarse como eternismo fundamentalista. Eternismo, porque mal interpreta el concepto de eternidad y solo es capaz de representárselo como atemporalidad, y fundamentalista, porque pretende validarse como unívoco fundamento de la permanencia de la verdad. En aras de la verdad se niega la historia bajo el supuesto de que la verdad no puede ser histórica. El tiempo es considerado sin más como negación de esa "permanencia en la unidad" (Timeo). Este planteo le debe más al mito que a la filosofía griega y populariza imaginativamente el concepto filosófico de eternidad. Es un tipo que en el último tiempo se ha visto favorecido por la revalorización del mito y sobre todo por la búsqueda de certezas que permitan poner coto al relativismo derivado de la modernidad y su consecuente "hermenéutica de la sospecha" (cf. por ejemplo en esta línea, algunos planteos de R. Spaemman y P. Koslowski). Como un segundo tipo para evadir las preguntas que plantea al hombre su experiencia del tiempo, tenemos el escapismo místico. En este caso se da una correlación entre simplificación de las preguntas que plantea la inmanencia histórica y un rápido recurso a la trascendencia como alteridad no mediable (como ejemplo de esto se puede señalar a B. Forte (127)). Más que ante una teología de la historia, como pretende este teólogo italiano, estamos ante una "doxología del Otro", que no puede mediar con el hombre en cuanto sujeto concreto, porque este, en su determinada situación histórica y a pesar de las buenas intenciones de rescatar su "condición exodal", solo es considerado en una noche tan tenebrosa como moderna de negatividad (por eso no resulta sorprendente que el planteo de Noemi se sienta más cómodo con la filosofía de la "alteridad" de Ricoeur

(123) Cf. ibíd., 2901-2980.

(124) Cf. ibíd., 3000.

(125) Cf. Der Glaube vor dem Anspruch der Wissenschaft, Friburgo 1968, 17-45.

(126) Cf. Esperanza en busca de inteligencia, 37ss; ver también del mismo autor, El mundo, especialmente 166ss.419ss. 485ss.545ss; Teologías de la historia en el umbral del tercer milenio, en: Caminando hacia el tercer milenio (Sociedad Argentina de Teología), Buenos Aires 1997, 91140; cf. también las profundas reflexiones de P. Hünermann, Geschichte versus Heilsgeschichte, Theologie und Glaube 90 (2000), 167-180.

(127) Cf. la reseña de J. Noemi al libro Teología de la historia. ensayo sobre revelación, teología y escatología del autor italiano en Teología y Vida 37 (1996), 263-264. 
que con la de Levinas). Finalmente está el tipo de fuga temporis, que, como diagnostica Noemi, es el más sofisticado y consiste en un recurso abusivo a la "paradoja" como categoría teológica. Se establece en dependencia inmediata de Kierkegaard y K. Barth. Noemi lo denomina paradojismo supranaturalista en atención a la crítica que del mismo realiza $\mathrm{P}$. Tillich y a una variante más reciente en algunos teólogos católicos (128). Según Noemi, se hace un recurso abusivo a la índole paradójica del mensaje evangélico y del cristianismo, en la medida que no se mantiene vivo el carácter dialéctico que rige entre trascendencia e inmanencia y se recurre a la trascendencia del cristianismo como un "no", una negación cosificada sobre la inmanencia. Este abuso tiene su raíz en el mismo Kierkegaard, quien en reacción al sistema especulativo de Hegel contrapone mediación y paradoja. La realidad del Dios hecho hombre, la consistencia de "la verdad eterna devenida en el tiempo", para Kierkegaard, solo es receptible por el entendimiento humano negativamente como "lo absurdo" y en el hombre es positiva exclusivamente como "pasión de la fe". Cuando K. Barth, recurriendo a Kierkegaard, planteó su programa de una "teología dialéctica", fue duramente criticado por $\mathrm{P}$. Tillich debido a un recurso nodialéctico a la paradoja. A juicio de Tillich, el recurso a la "infinita diferencia cualitativa de tiempo y eternidad" se torna contradictorio consigo mismo cuando se detiene y especifica como pura negación de la inmanencia por parte de la trascendencia. Así, desentenderse de la positividad con que lo inmanente remite ontológicamente a lo trascendente conduce a una "teología del absurdo positivo". Toda negación explícita se torna contradictoria consigo misma si no reconoce el sí que presupone. Según Tillich, si Barth es consecuente con su planteo es preciso un "retroceso de la paradoja crítica a la paradoja positiva". El peligro de supranaturalismo es en última instancia su capacidad de condicionar un recurso adialéctico a la paradoja. Esta herencia barthiana puede conducir en la teología católica al hecho que la voluntas catholica reemplaza a la demonstratio catholica, se extravía de la tarea que le planteó el Concilio Vaticano I a la teología, y al desentenderse de que la fe es un obsequium rationi consentaneum (DH 3009) puede incluso malentenderse como apodíctica gnóstica.

Sobre este trasfondo -de pensar la historia más que condenarla, o, dicho de otra forma, que sea tema y no anatema- es donde se debe situar el alcance de las palabras clave del magisterio de Juan XXIII. La categoría de los "signos de los tiempos" es, por tanto, coherente con las de carácter pastoral y aggiornamento, y traduce la concepción que ese Papa tenía de la doctrina cristiana y del magisterio. Los "signos de los tiempos" permiten redescubrir la juventud del Evangelio, captando en él, gracias al Espíritu, posibilidades que las interpretaciones anteriores no habían captado. Bien mirado, este es el significado de la concepción de la tradición como "epíclesis" del Espíritu sobre la historia, con lo cual se subraya que ahora es la historia vivida realmente por los hombres la que debe quedar revestida de la energía del Espíritu de Cristo. Aquí se encuentra el significado histórico-teológico de la categoría de los "signos de los tiempos". La historia, no solo la del pasado,

(128) Para un resumen, cf. Esperanza en busca de inteligencia, 37ss; íd., P. Tillich: un teólogo sistemático protestante, en: AAVV, Grandes teólogos, 95-114. 
sino sobre todo la presente, con las vicisitudes vividas por los hombres de nuestro tiempo, es locus theologicus (129). Como ya hemos precisado, en esta afirmación no se trata de la visión tradicional que consideraba como lugar teológico sobre todo la historia narrada, los documentos del pasado de los que se pueden obtener argumentos en favor de la verdad católica. No es la simple historia documentada, pero tampoco la simple historia vivida, las que pueden hacer aparecer sus signos distintivos como lugar de una renovada presencia del Espíritu de Cristo. Por lo demás, la historia está siempre mediada por una cultura, por una memoria colectiva y, en las sociedades en las cuales rige una transmisión organizada del saber, por los reflejos de la conciencia crítica de la historia misma. Se da sobre todo historia humana allí donde se tiene una conciencia consciente, críticamente fundada, del significado de la vicisitud humana y de los acaecimientos vividos en el presente, no solo como fruto de las posibilidades depositadas por los hombres en el pasado, sino también como destrucción de dichas posibilidades, y por tanto como negación. En la historia se dan también los escombros, lo que desaparece para siempre. A través de las expectativas mesiánicas nos llega precisamente una visión de la historia que mantiene el recuerdo de sus sufrimientos y, por tanto, lucha por un futuro reconciliado. Para la teología será siempre útil recordar en este punto el pensamiento de W. Benjamín, que influyó, entre otros, a Metz.

A continuación realizaremos un brevísimo esbozo del planteo de Metz con respecto al tema que venimos tratando, pues, más allá de la recepción crítica del que este ha sido objeto, representa, a nuestro entender, uno de los ensayos más profundos por repensar las relaciones entre teología e historia bajo el impulso que el último concilio supuso para el pensar teológico. Además, el detenernos en Metz nos parece especialmente útil, pues es sin duda una de los planteos postconciliares que más ha influido en la teología latinoamericana en vistas a la recuperación de lo histórico -y con ello la temática los signos de los tiempos- para la razón teológica.

\subsection{Recuperar el tiempo y la historia como tema teo-lógico fundamental. El planteo de Metz. (130)}

Metz desarrolla unas tesis sobre la apocalíptica, que tienen una función preferentemente correctiva, con el fin de tematizar el factor "tiempo" en la teología y en el cristianismo. La acentuación del carácter expectante de la esperanza cristiana tiene por objeto someter la praxis de los cristianos a la presión del tiempo. Metz

(129) Cf. G. Ruggieri, La storia come luogo, 319-337; P. Hünermann, Neue Loci theologici, 1-21, especialmente $15 \mathrm{ss}$

(130) De la obra de Metz hemos recurrido fundamentalmente a La fe en la historia y en la sociedad. Esbozo de teología política, Madrid 1979. Para una recepción crítico-valorativa del planteo de Metz, cf. J. Noemi, El mundo, 241-244; J. H. Tück, Christologie und Theodizee bei Johann Baptist Metz. Ambivalenz der Neuzeit im Lichte der Gottesfrage, Schöningh 1999; R. Jahae, Erlösung-Errinerung-Hoffnung. Überlegungen zur Soteriologie Johann Baptist Metz, Theologie und Philosophie 79 (2004), 73-89 (este artículo es especialmente interesante por subrayar las relaciones entre el pensamiento de Metz y algunas de sus ideas presentes en el Vaticano II que hemos expuesto en este artículo); G. Essen, Geschichte als Sinnproblem. Zum Verhältnis von Theologie und Historik, Theologie und Philosophie 71 (1996), 330ss; J. M. Mardones, Recuperar la justicia. Religión y política en una sociedad laica, Santander 2005. 
desea recordar que la "sabiduría apocalíptica" en el cristianismo están interrumpidas desde hace tiempo.

Metz habla así de "síntomas de intemporalidad", subrayando que la época contemporánea es la de la falta de tiempo: ¿no será esta expresión de un derrotismo, de una forma especial de resignación, producida por la experiencia de un tiempo sin tiempo?

Existe hoy, como señala este teólogo, un culto a la factibilidad. Pero también, subraya, existe un nuevo culto a la fatalidad. La "voluntad de hacer" está transida de resignación. Ambos cultos, el que tiende a dominar la fatalidad y el que se complace en la apatía y en la vida apolítica, se corresponden como las dos caras de la misma moneda. El concepto de realidad que preside la explotación científico-técnica de la naturaleza y de la que se nutre el culto a la producción está regido por una idea del tiempo como un continuum vacío que evoluciona hacia el infinito, en que todo está inexorablemente incluido; esta idea excluye toda expectativa sustancial y engendra ese fatalismo que corroe el alma del hombre moderno. Así, este hombre -cual Godot- está ya resignado antes de que la sociedad le haya ejercitado en la resignación bajo el lema de la "racionalidad pragmática". En este momento de la reflexión Metz introduce la idea de religión como "interrupción".

Nos recuerda este teólogo las primeras categorías de la interrupción: amor, solidaridad que se "toma" tiempo, y recuerdo, que no solo evoca lo logrado, sino lo destruido; y así se vuelve contra el triunfalismo de lo madurado y permanente: peligroso recuerdo que, así justamente, salva el "continuum cristiano". Este acercamiento a lo religioso como interrupción lo confronta con la problemática de la "intemporalidad como sistema".

Hay un sustitutivo de la metafísica cuyo nombre es "lógica de la evolución". En ella, el indiferentismo del tiempo ha alcanzado su predominio sistemático sobre la conciencia general. Sobre ella se "reconstruye" todo en continuidad intemporal: tanto la conciencia religiosa como la conciencia dialéctica y religioso-crítica.

No se refiere aquí Metz al uso ideológico de "desarrollo", es decir, a la generalización del símbolo de una evolución sin término. Así, pues, la crítica de la lógica de la evolución absoluta ayuda a clarificar y establecer los límites del status teórico de la evolución.

Ya hace mucho tiempo que han cambiado los símbolos para la comprensión del tiempo nos recuerda Metz. El simbolismo apocalíptico del derrumbamiento fue sustituido por el símbolo pseudorreligioso de la evolución.

En cualquier caso, prosigue Metz, la civilización científico-técnica no es un "universo racional". Su mito es la evolución. El interés secreto de su racionalidad es la ficción del tiempo como una infinitud vacía y exenta de sorpresas, en la que todo y todos están inexorablemente incluidos. Las manifestaciones sociales de todo esto difícilmente pueden pasar inadvertidas: de un lado, la creciente apatía; de otro, el odio irracional; fatalismo en un extremo y fanatismo en otro.

Ahora bien, se pregunta Metz, ¿cómo debe reaccionar la teología frente a la intemporalidad recién descrita?

La "expectativa cercana" (Naherwartung) del Nuevo Testamento, para una conciencia habituada a considerar el tiempo como una infinitud vacía, neutralizada en sentido evolucionista, resulta una exigencia inaceptable. Sin embargo, la versión 
interpretativa que la teología ha hecho de la "expectativa cercana" como "expectativa permanente" es un fraude semántico contra la estructura temporal básica del cristianismo, cuyo núcleo es "temporal"; esta interpretación confirma indirectamente hasta qué punto la teología misma ha sucumbido a una destrucción evolucionista del tiempo. Pero una teología que se somete sin crítica de ningún tipo a la concepción de un historicismo evolucionista, con la pérdida de la "expectativa cercana" acabará perdiendo todo lo demás .

Metz señala que hace tiempo que la teología ha adherido al evolucionismo. Pero esta adhesión conlleva graves costos. La lógica de la evolución significa el predominio de la muerte sobre la historia: todo resulta al final igualmente indiferente. Para esta lógica el Dios de los vivos y los muertos en paz, es sencillamente impensable.

Así llega Metz a diagnosticar a una teología fascinada por la intemporalidad: la concentración del carácter temporal del cristianismo en el tiempo de la existencia tampoco rompe la fascinación, pues lleva a la contraposición paradójica de tiempo y eternidad. Pero la "eternidad", como lo contrario del tiempo humano, no es Dios, sino naturaleza o, más exactamente, Deus sive natura. Dios no es, según la Biblia, lo otro que el tiempo, sino su fin, su límite, su ruptura y, justamente por ello, su posibilidad.

Bajo el predominio de un ideal evolucionista del tiempo, la idea del "reino de Dios" es, subraya Metz, rigurosamente destemporalizada por unos e integrada por otros en un esquema evolucionista en el que la categoría de la consumación está ya calculada de forma procesual-evolutiva: el reino de Dios se convierte en mera utopía que se va realizando a lo largo del "progreso" (131). Ambos planteamientos traicionan el núcleo temporal específico del mensaje del reino de Dios. Lo anterior lleva a Metz a cuestionarse: ¿es aún pensable siquiera un límite y un fin del tiempo, o no se ha convertido ya mucho antes la expectativa de un fin del tiempo en la expresión de una escatología mítica, dado que el tiempo mismo se nos ha vuelto entre tanto un continuum homogéneo que no reserva sorpresas?

De esta manera, el programa teológico de Metz propone que contra la fascinación de la intemporalidad se repiense la apocalíptica.

Lo que rompe el hechizo de la intemporalidad es así la conciencia teológica que no se deja quitar por la evolución el aguijón apocalíptico.

La auténtica apocalíptica judeocristiana fue, a juicio de Metz, el correlato místico de una realidad política vivida. Para saber qué tipo de realidad política fue esta basta con echar una mirada a la historia de las religiones y en especial al Nuevo Testamento: fueron tiempos de crisis.

Si lo primero que vemos en la apocalíptica judeocristiana es la radical temporalización del mundo, entonces la conciencia catastrófica de la apocalíptica es fundamentalmente una conciencia del tiempo, de la esencia catastrófica del tiempo mismo, del carácter de discontinuidad, ruptura y finitud del tiempo. Esta esencia catastrófica del tiempo hace el futuro problemático. Mas justamente por ello el futuro se convierte en "auténtico futuro", cobra su estructura temporal y pierde ese

(131) Cf. las reflexiones de F. Castillo en: J. Noemi/F. Castillo, Teología latinoamericana, Santiago 1998,113 ss. 
carácter de infinitud intemporal, en la que arbitrariamente se proyecta y extrapola el presente.

En este contexto Metz postula que la cristología sin la apocalíptica se convierte en ideología de vencedores.

La idea cristiana del seguimiento y la idea apocalíptica de expectativa cercana van necesariamente unidas. El seguimiento de Jesús, entendido de modo radical, esto es, en su raíz, no puede vivirse si no se abrevia el tiempo. La llamada de Jesús al seguimiento, y la invocación de los cristianos: “¡Ven, Señor Jesús!”, son inseparables. Seguimiento en expectativa cercana: tal es la conciencia apocalíptica que asume el sufrimiento, desafiando a la apatía tanto como al odio.

La expectativa dolorosa del "día del Señor" no admite así dilación ninguna del seguimiento; la expectativa cercana confiere a la esperanza aquietada por la idea evolucionista unas perspectivas de expectación y tiempo. La expectativa cercana trae a la vida cristiana el apremio del tiempo y de la acción, fundamentando la responsabilidad. La conciencia apocalíptica se presenta de esta manera bajo el signo del reto a la solidaridad práctica con los "hermanos más débiles".

Por último, de lo dicho sobre Metz se puede afirmar que el diagnóstico estructural de nuestro tiempo es colocado en el marco del mensaje escatológico cristiano, cuyos impulsos, mirando al futuro del Crucificado Resucitado, se vuelven críticos, mesiánicos, desacreditadores de una sociedad que no responde a las expectativas del Reino. Desde la promesa de una gran justicia o justicia absoluta, se desata la pregunta por las desigualdades, injusticias y sufrimientos de este mundo. Crece la urgencia de no seguir adelante y de poner fin a esta historia de sufrimientos. Este tono escatológico, incluso apocalíptico, señala la impronta de una sensibilidad teológica que descubre que toda la teología cristiana es escatológica, y toda teología escatológica que mira al futuro del Resucitado no puede por menos que convertirse en mirada crítica hacia la sociedad presente. Es decir, la teología escatológica se torna teología política como crítica de la sociedad. La confrontación con la política y el análisis social e ideológico es la dramatización en clave de crítica social del problema de la teodicea, es decir, del acercamiento de la teología al sufrimiento social y sus causas. En el fondo late la inquietud que despierta la historia de sufrimiento de los hombres y el interrogante sobre Dios en esta situación como clamor por la salvación de los otros. Desde este punto de vista se comprende la denuncia persistente de Metz de un cristianismo que ha cambiado una moral del sufrimiento por una moral del pecado extraordinariamente individualizada. La atención primordial se ha desplazado del sufrimiento de la criatura a la culpa: "La predicación cristiana se convirtió en una heurística de los sufrimientos de culpa y de la angustia por el pecado. Esto paralizó su sensibilidad hacia el sufrimiento de los inocentes y oscureció la visión bíblica de la gran justicia de Dios, que atiende a todos los que padecen hambre y sed" (132).

Una mirada que funciona más crítico-negativamente que como propuesta positiva del tipo de sociedad que hay que construir, señala lo que no debe repetirse ni proseguir y, de esta forma, apunta hacia una mayor humanización (133).

(132) J. B. Metz, El clamor de la tierra, Estella 1996, 13.

(133) Cf. íd., Por una cultura de la memoria, Barcelona 1999, 26-35. 


\section{HACIA UNA SUPERACIÓN DEL CARÁCTER EXTRÍNSECO DE LA HISTORIA HUMANA EN Y PARA LA TEOLOGÍA. A MODO DE CONCLUSIÓN}

Las reflexiones sobre la temática del "tiempo" y el planteo de Metz que hemos realizado en los dos últimos puntos, nos indican la posibilidad de una integración de la historia y de sus signos distintivos en el conocimiento teológico, integración menos "extrínseca" de lo que pensaba el mismo Cano. El Vaticano II, en la Constitución Gaudium et spes no 44 , reconoce explícitamente este carácter no extrínseco de la historia humana cuando afirma que la Iglesia "reconoce los muchos beneficios que ha recibido de la evolución histórica del genero humano" ( $\left.\mathrm{n}^{0} 44\right)$. Se habla, pues, de un commercium augendum, de un intercambio que debe incrementarse entre historia e Iglesia (134), sobre todo en la evangelización.

Esta afirmación presupone, obviamente, que la economía cristiana de la salvación es una economía histórica, por tanto in fieri (en proceso) No se entenderá, pues, el papel cognoscitivo de los signos de los tiempos mientras se siga cautivo de una concepción "objetivista" de la revelación cristiana, pasando por alto que esta no posee solo su momento "fundante", sino que también está siempre in actu. Los signos de los tiempos no son "externos" a la economía salvífica, sino que la constituyen juntamente con la epíclesis del Espíritu de Cristo, crucificado y resucitado.

Por lo demás, la expresión "signos de los tiempos", en el único pasaje neotestamentario donde aparece, Mt 16,3, denota los signos del tiempo mesiánico, es decir, las palabras y gestos de Jesús de Nazaret (como bien subraya Ruggieri, él es el analogatum princeps en la temática de los "signos de los tiempos" (135)). Cristo hace realidad los tiempos mesiánicos previstos por los profetas, que sus interlocutores no saben ver. Como bien anota al respecto J. Gnilka: "El concepto de tiempo kairoj se refiere al punto del tiempo, al tiempo presente, que es tiempo de decisión. En la conversación con Jesús se quiere referir los kairoi a él, a sus obras y a su persona" (136). El texto paralelo de Lc 12,56 no contiene la expresión "signos de los tiempos", sino kairos, el tiempo cualificado en el que se ofrece al hombre la gracia de Dios; como afirma con respecto a este texto lucano K. Scholtissek "Decisivo es aquel kairos histórico-salvífico cualificado por Jesús y su envío: él mismo es en persona el signo de Dios definitivo, él es la signatura (Signatur) del kairos" (137). También en él, como en Mateo, el significado de la expresión es, pues, cristológica y escatológica al mismo tiempo. De algún modo, el único signo de los tiempos es Cristo mismo. A partir de aquí, y de la presencia de Cristo en la Iglesia gracias a su Espíritu, pero también en la creación entera, es posible documentar cómo en el Nuevo Testamento este kairos, este momento oportuno de la gracia, atraviesa la historia entera hasta el último advenimiento y la reconciliación final de todas las cosas.

(134) Cf. G. Essen, Geschichte, $321 \mathrm{ss}$.

(135) La teologia dei, 56.

(136) Das Matthäusevangelium, vol. 2, Freiburg 1988, 41.

(137) “Könnt ihr die Zeichen der Zeit deuten?” (vgl. Lk 12,56). Christologie und Kairologie im Lukanischen Doppelwerk, Theologie und Glaube 85 (1995), 220, interesante resulta seguir también la perspectiva pneumatológica-histórica que el autor le confiere a la temática de los "signos de los tiempos" en el corpus lucano (cf. 219ss, especialmente 222-223 y n. 154) sobre la que nosotros hemos insistido en nuestras reflexiones. 
La cuestión hermenéutica fundamental, pues, se debe formular así: ¿por qué en la historia de Jesús de Nazaret adviene el reino de Dios, por qué debemos reconocer en ella el signo de los tiempos, el kairos? Nótese bien que no se trata de una historia solo en positivo, a saber, la de los milagros, sino también en negativo, ya que su momento decisivo es precisamente la muerte en la cruz, el abandono de Dios (como en el libro La noche de E. Wiesel), el descenso a los infiernos, al menos si lo entendemos como la prolongación del abandono de Dios en la cruz (138).

La respuesta que se puede dar, a partir de la perspectiva global del Nuevo Testamento, es que Dios ha alcanzado en Cristo a todo hombre y toda cosa, reconciliándolos consigo, "trocándolos" por Cristo, ya que Cristo es esa reconciliación/ trueque global. En él adviene el reino (Orígenes), él es, por tanto, el signo de los tiempos tan esperado, porque en él Dios alcanza y acoge ya a todo hombre, en primer lugar al que estaba perdido, al pecador (139). Nada ilustra esto mejor que el texto de 2 Cor 5,17-21. En él, la novedad del acontecimiento cristiano se funda en un "trueque". Aquel que no conocía pecado fue hecho pecado, para que nosotros nos hiciésemos "en él" justicia de Dios. Con este trueque que es uno de los aspectos esenciales del acontecimiento cristológico, en el cual todo pecador es alcanzado por Dios, hemos sido reconciliados con Dios. Es decir, en Cristo todo hombre ha sido acogido en Dios. Con otra expresión paulina podemos decir que en Cristo se da el sí definitivo de Dios al hombre. En la entrega de Cristo a los hombres adviene el reino mesiánico, y por eso él es "el signo de los tiempos": en él han pasado las cosas viejas y han nacido las nuevas. No hay que olvidar en este punto la advertencia de K. Füssel (140), en relación al rol del Espíritu, al que se alude en nuestras reflexiones, en el contexto de una teología de los signos de los tiempos.

Lo que es preciso señalar en los confines de una hermenéutica de los "signos de los tiempos" es la convicción creyente de que en Cristo toda la historia, hasta la de la muerte y el pecado, ha sido alcanzada y redimida. No solo la curación del enfermo, no solo el pan para las multitudes hambrientas, sino también la muerte y la aniquilación son, en el "trueque" cristológico, señales del advenimiento de Dios a la historia. Incluso la ausencia de Dios ("Dios mío, Dios mío, por qué me has abandonado"), que constituye la experiencia de la muerte, debe ser reconocida en Cristo por los creyentes como signo de los tiempos mesiánicos. Su muerte queda connotada como una "muerte por": su cuerpo fue entregado por nosotros, murió por nuestros pecados, etc.

Otro modo de acercarnos al núcleo del problema lo ofrece la discusión historiográfica, sobre todo en el ámbito francés, acerca de la relación entre longue duuré y evenement. Dentro de la llamada "Escuela de los Annales", se había afianzado toda una tendencia, en la interpretación de la historia, atenta a los factores de larga

(138) Cf. H. U. von Balthasar, El misterio pascual, en: J. Feiner/M. Löhrer (eds.), Mysterium Salutis, vol. 3, Madrid 21980, 666-809.

(139) Cf. G. Ruggieri, La teologia dei, 60ss; para el texto de 2 Cor 5, 17-21 cf. J. D. G. Dunn, The Theology of Paul the Apostle, Grand Rapids 1998, sobre todo sus reflexiones sobre la "reconciliación”, 228ss; para una reflexión sistemática cf. H. U. von Balthasar, Teodramática, vol. 3, Madrid 1993, 220ss; E. Przywara, Commercium, en: íd, Logos, Düsseldorf 1964, 119-165.

(140) Die Zeichen der Zeit als locus theologicus, Freiburger Zeitschrift für Philosophie und Theologie 30 (1983), 259-274. 
duración, a las constantes (climáticas, económicas, mentales, etc.) de la vida humana, mientras que los acontecimientos, "los hechos que hacen ruido", eran considerados más bien signos indicadores de la realidad duradera y de las estructuras fundamentales. Contra esta tendencia se ha reafirmado en cambio, más recientemente, el papel del acontecimiento, de un hecho o de una serie de hechos, que determinan el paso de una estructura a otra, que cambian, por tanto, la historia (141). Es interesante notar al respecto cómo en un reciente estudio sobre las relaciones entre Rahner y el Vaticano II, G. Wassilowsky (142) ha señalado cómo Rahner ha captado muy bien que junto con la interpretación del concilio al interior de la longue duré se debe estar atento a su carácter innovativo.

Extrapolando los términos de esta discusión, podemos decir que un acontecimiento aporta novedad a la historia en tanto en cuanto está en disposición de modificar aquellas estructuras de las relaciones humanas que constituían el equilibrio precedente. Es innegable, por ejemplo, que la Reforma luterana, con todos los factores que la constituyeron -desde la predicación de Lutero a los Flugschriften, que difundieron su pensamiento y crearon el primer gran movimiento auténtico de opinión de la historia moderna, desde la implicación en ella de algunas clases sociales a la aparición de un "nuevo" sujeto eclesial como los laicos-, fue un acontecimiento capaz de modificar, en el plano de la larga duración, la vida religiosa de los pueblos europeos. También es probable, por poner un ejemplo contemporáneo, que el Vaticano II haya sido un acontecimiento capaz de modificar establemente la mentalidad y los comportamientos de todos los cristianos, y no solo de los católicos de nuestro tiempo (143).

A la luz de estas reflexiones podemos intentar una determinación ulterior de los "signos de los tiempos". Un hecho es susceptible de convertirse en "signo de los tiempos" cuando, gracias a la toma de conciencia colectiva, está en condiciones de modificar en dirección mesiánica el equilibrio de las relaciones humanas de una época determinada. Para que eso suceda es determinante la toma de conciencia colectiva. Una eventual erupción submarina que convulsionase el equilibrio climático del planeta no sería aún un signo de los tiempos. Pero la toma de conciencia colectiva de la destrucción de la naturaleza realizada por la cultura exacerbada del homo faber, toma de conciencia colectiva que contribuye a determinar un nuevo sentido de responsabilidad respecto a las generaciones futuras, es un signo de los tiempos. En esta toma de conciencia, y no en la destrucción de la naturaleza como tal, se anuncia un futuro con un menor número de muertos, con un estilo de vida menos violento y más sobrio; por eso es legítimo verla como una señal de la creación que espera la liberación.

Para terminar, baste con poner un ejemplo más. La pobreza en la que se encuentran viviendo muchedumbres inmensas de hombres todavía no es, como tal,

(141) Cf. P. Burke, La revolución historiográfica francesa, Barcelona 1994.

(142) Cf. K. Rahners, 45ss.

(143) Cf. E. Fouilloux, La categoría di evento nella storiografia francesa recente, en: M. T. Fattori/A. Melloni (eds.), L'evento e le decisión. Studi sulle dinamiche del concilio Vaticano II, Bolonia 1997, 51-62; J. A. Komonchak, Riflessioni storiografiche sul Vaticano II como evento, en: ibíd., 417-439. 
un "signo de los tiempos". Tampoco lo es cuando suscita un movimiento de solidaridad. La historia de la Iglesia está llena de testimonios de caridad para con los pobres, pero, excepto quizás en los tiempos primitivos del franciscanismo, esto no ha supuesto una nueva consideración efectiva del Evangelio. Solo cuando algunos hombres comienzan a colocar la pobreza a la luz mesiánica y descubren un nuevo equilibrio en el Evangelio y en la Iglesia, para los cuales el misterio de la pobreza -en los pobres y en Cristo, que se hizo pobre- se convierte en el eje de la historia, el Evangelio se vuelve Evangelio de los pobres, y la Iglesia se vuelve Iglesia de los pobres... solo entonces comienzan los hombres a reconocer un signo de los tiempos (144).

\title{
RESUMEN
}

Inspirándose en la figura de Monseñor Manuel Larraín, este artículo pretende señalar la importancia de la categoría "signos de los tiempos" para una reflexión católica actual que aspire a tener identidad y relevancia en la sociedad moderna. Bajo esta categoría el Concilio Vaticano II ha señalado acontecimientos históricos o realidades en los cuales el Espíritu de Dios y sus obras resplandecen. El concilio ha exhortado a los cristianos a tomar en serio esos signos y ha reconocer en ellos la presencia y llamado de Dios. A partir de esto, la reflexión cristiana y la teología se enfrentan al reto de pensar las realidades humano-divinas no como una simple paradoja, sino al interior de una estructura de "identidad y diferencia".

\begin{abstract}
Taking its inspiration from the figure of the Catholic bishop, Mons. Manuel Larraín, this article endeavors to indicate the importance of the category of "signs of the times" for a current Catholic reflection that aspires to have identity and relevance for modern society. Under this category the Second Vatican Council has indicated historic events or realities in which the Spirit of God and God's works stand out. The Council has exhorted Christians to take those signs seriously and has recognized in them the presence and summons of God. From this startingpoint, Christian reflection and theology confront the challenge of thinking about human-divine realities not as a simple paradox, but from the interior of a structure of "identity and difference".
\end{abstract}

(144) Cf. para el tema de los signos de los tiempos en la teología latinoamericana, José I. González Faus, Las víctimas como lugar teológico, Revista Latinoamericana de Teología 46 (1999), 89104; J. Sobrino, Le fe en Jesucristo. Ensayo desde las víctimas, Madrid 1999. 